\title{
Alliance management knowledge and alliance performance: unveiling the moderating role of the dedicated alliance function
}

\section{Angeloantonio Russo $\mathbb{( i )}^{1, *}$ and Clodia Vurro $\mathbb{1}^{2}{ }^{2}$}

${ }^{1}$ Department of Management, LUM Jean Monnet University, S.S. 100 km 18, Casamassima, Bari 70010, Italy. e-mail: russo@lum.it and ${ }^{2}$ Department of Economics, Management and Quantitative Methods, University of Milan, Via Conservatorio, 7, Milan 20122, Italy. e-mail: clodia.vurro@unimi.it

*Main author for correspondence.

\section{Abstract}

This study attempts to increase the understanding of how different solutions to build alliance management capability influence alliance performance. We propose that both reliance on the informal accumulation of alliance experience (i.e., tacit alliance management knowledge, AMK) and articulation of alliance know-how in the form of usable guidelines, checklists, or manuals (i.e., codified AMK) have an inverted U-shaped influence on alliance performance. Additionally, we investigate the moderating role of having the dedicated alliance function (DAF) on the curvilinear relationships between reliance on AMK and performance. Based on a sample of 113 large firms involved in strategic alliances, we find support for the inverted U-shaped relationship between reliance on tacit and codified AMK and alliance performance. Moreover, our results indicate that the DAF has a positive impact on the deployment of AMK. The DAF turns into improved performance when the reliance on experiential learning and the codification of AMK are both limited. Moreover, the DAF also reduces the potential downside effects of relying on higher levels of both types of AMK. Finally, DAF diversity, in terms of educational, functional, and tenure heterogeneity of its members, emerges as relevant to achieve effective alliance know-how collection and deployment for superior alliance performance.

JEL classification: L10, L21, L24

\section{Introduction}

In a fast changing and hypercompetitive world, alliances have become a key tool to access valuable and non-tradable resources (Das and Teng, 2000) and an important source of competitive advantage (Dyer and Singh, 1998) and value creation (Anand and Khanna, 2000). Notwithstanding the increasing need to rely on these inter-organizational partnerships to compete, alliances are complex to manage and fraught with risks. Empirical evidence shows that most of them fail to live up to performance expectations (Koza and Lewin, 2000; Kale et al., 2001), and they can lead to destruction of shareholder value (Kale et al., 2002).

Moving from the strategic importance of these inter-firm collaborations, recent studies have increasingly focused on the performance consequences of organizational arrangements that facilitate the accumulation and sharing of 
alliance management knowledge (AMK, hereafter) embedded in prior and ongoing alliance experience (Heimeriks et al., 2009; Niesten and Jolink, 2015). A significant body of empirical research has stressed the positive impact of relying on accumulated alliance experience and informal sharing of lessons learned, that is, tacit AMK (Heimeriks and Duysters, 2007). Yet, the deployment of tacit AMK is a necessary but not sufficient condition to improve alliance performance. Scholars have provided empirical evidence on the need to implement more proactive efforts to articulate tacitness into usable, codified objects, that is, codified AMK (Wang and Rajagopalan, 2015). The use of such codified tools is expected to support alliance decision-making in alliance transactions and improve performance (Zollo and Winter, 2002; Håkanson, 2007).

Despite converging on the potential gains of deploying tacit and codified AMK, recent research has started to address the potential drawbacks of reliance on both types of knowledge (Kale and Singh, 2009; Wang and Rajagopalan, 2015). In fact, excessive reliance on tacitness may result in inertial behavior and foster overconfidence and superstitious learning phenomena (Hoang and Rothaermel, 2005). Similarly, an increasing level of codification may exhibit diminishing returns due to the fallacies of detachment, predetermination, and formalization (Heimeriks, 2010).

In an attempt to better handle the limits of reliance on tacit and codified AMK, dedicated alliance functions (DAFs) are emerging across industries. Defined as that organizational unit directly responsible for coordinating and monitoring the firm's alliances, the DAF is purposefully created to manage complex learning processes, support the accumulation and deployment of alliance management know-how, identify, screen, and attract prospective alliance partners (Kale and Singh, 1999; Wang and Rajagopalan, 2015). Research has already confirmed an overall positive impact of establishing the DAF on alliance performance (Kale et al., 2002; Heimeriks et al., 2009). Yet, evidence is still anecdotal on the moderating role of the DAF in the deployment of AMK for superior performance.

Moving from the above theoretical arguments, we address the benefits and costs of deploying tacit and codified AMK. First, we suggest that the relationship between reliance on these types of knowledge and alliance performance is not linear but may follow an inverted U-shape. Second, we argue that the contribution of reliance on experiential learning and codification of alliance know-how to alliance performance is contingent on the existence of the DAF. Third, we explore and empirically test how specific attributes of the DAF, namely, its educational, functional, and tenure diversity, affect the relationship between reliance on AMK and alliance performance.

To test the hypotheses, we collected primary data in a sample of 113 large companies extensively involved in strategic alliances. Given the objectives of this study, a survey represented the most appropriate method to collect data and information for the variable included in the analysis: the dependent variable (i.e., alliance performance), predictors (i.e., tacit and codified AMK), and moderators (i.e., the presence of the DAF and its diversity) of the relationship between predictors and the dependent variable.

Results provide support to the non-linearity hypotheses. Reliance on AMK exhibits a pattern of diminishing returns, eventually reversing itself at high levels when companies may find themselves stuck in either experiential learning traps or excessive codification (Heimeriks et al., 2007). By focusing on the distinct effects of reliance on AMK and suggesting an inverted U-shaped relationship, our study provides insights into the antecedents of alliance success as it integrates and extends current perspectives on the benefits and limits of investing in learning processes to build alliance capability. In this vein, we provide a knowledge-based explanation for the previously inverse U-relationship between the intensity to which firms engage in external collaborations and the returns they receive from this engagement (Deeds and Hill, 1996; Hottenrott and Lopes-Bento, 2016).

Moreover, results indicate that having the DAF improves alliance performance when the development of alliance management capabilities to use AMK is still limited. The DAF also reduces the potential downside effects of high reliance on both types of alliance knowledge. Evidence of the moderating role of the DAF is further extended by disentangling the impact of a more or less diverse composition of its members, in terms of education, represented functions, and tenure. Results show that as diversity grows, it improves alliance performance consequences of lower and higher reliance on both types of knowledge. By highlighting DAFs' attributes as important contingency factors, we answer the call for a better understanding of how to properly set up an alliance function (Kale and Singh, 2009). 


\section{Theory and hypotheses}

\subsection{Alliance management knowledge deployment and alliance success}

\subsubsection{The pros and cons of relying on tacit AMK}

The past decades have witnessed growing evidence that firms accumulate AMK doing more of the same (i.e., experiential knowledge without explicit knowledge codification), and therefore, tacitly developing alliance capability (Anand and Khanna, 2000). This type of knowledge is defined as tacit because it originates as individual experiences and perceptions (Ancori et al., 2000; Foss, 2003). Difficult to be formalized and articulated from practice, tacit knowledge is processed into collective understandings, competencies, know-how, and routines (Spender, 1996; Håkanson, 2007; Nonaka and von Krogh, 2009).

A substantial number of studies have supported the concept that firms learn from the tacit accumulation of prior alliance experience (Sampson, 2005; Schilke and Goerzen, 2010; Hottenrott and Lopes-Bento, 2015) and benefit from its deployment (Heimeriks and Duysters, 2007). Anand and Khanna (2000), for instance, were among the first to find that firms with greater experience in joint ventures learn to create more value and, therefore, generate higher stock returns.

There are several reasons supporting the belief that the use of tacit AMK acquired through experience turns into improved alliance performance (Russo and Vurro, 2010). First, firms with greater alliance experience improve their alliance performance through learning-by-doing and trial and error processes. These processes are fundamental to acquire experiential wisdom and create a portfolio of heuristics to guide the selection and retention of previous behaviors by elaborating and leveraging on a repertoire of positive or negative feedbacks (Levitt and March, 1988; Gavetti and Levinthal, 2000; Bingham and Eisenhardt, 2011). Indeed, managers usually reinforce behaviors that have shown positive outcomes, whereas diminishing the propensity to engage in actions and procedures that have led to negative consequences.

Further, companies that have engaged in numerous alliances are more familiar with critical alliance issues and processes (Heimeriks and Duysters, 2007), making them more able to assess risks and improve alliance performance (Sampson, 2005). Similarly, experienced managers are less prone to erroneously transfer processes and routines (Nadolska and Barkema, 2014).

Finally, the accumulation of alliance experience over time and across domains stimulates conscious learning and favors the emergence of a deliberate attitude to capture lessons learnt from earlier experiences (Simonin, 1997). Therefore, firms leverage on higher alliance experience to develop more effective alliance management systems.

However, accumulating alliance experience does not increase alliance performance indefinitely (Rothaermel and Deeds, 2006). Many studies have highlighted that although positive, the effect of the informal accumulation of experience has diminishing marginal returns (Draulans et al., 2003; Hoang and Rothaermel, 2005; Sampson, 2005). Anand and Khanna (2000) find that experience accounts only for a limited proportion of alliance success. Kale et al. (2001) highlight that the mere accumulation of tacit knowledge, which usually remains embedded into the minds of individual managers (Inkpen and Dinur, 1998), is a necessary but not sufficient condition to fully explain superior alliance skills.

There are numerous reasons suggesting that there is a limit to learning-by-doing and alliance experience accumulation (Nygaard and Russo, 2008). First, the development of routines from prior experience can lead to the reduction of the spectrum of options analyzed and implemented by the firm (Levinthal and March, 1993; Hoang and Rothaermel, 2005; Sampson, 2005). Second, the accumulation of previous success is likely to foster overconfidence and superstitious learning phenomena, limiting the development of deeper action-outcome linkages (Levitt and March, 1988; Zollo, 2009; Heimeriks, 2010). Third, the learning process takes place at an individual level and, thus, alliance know-how is likely to be embedded in the minds of the single managers directly involved, limiting the diffusion and further development of firm-wide alliance capabilities. In this regard, the beneficial impact of experiential alliance knowledge relates to the extent to which best practices are transferred within corporate boundaries (Szulanski, 1996). Yet, practices have a relevant tacit component, because of their embeddedness in individual skills and potentially complex social interactions. Consequently, it is reasonable to expect that when reliance on the transfer of best practices prevails, excessive tacitness results in barriers to imitation, transfer, and absorption of lessons learned from experience (Simonin, 1999), thus hindering alliance performance (Nielsen and Nielsen, 2009). In fact, 
knowledge stickiness results in higher costs of knowledge transfer related to the need for making highly embedded knowledge usable by other parties involved (Szulanski, 1996).

Considering the above arguments, we posit that tacit AMK does contribute to the overall alliance performance, but an upper limit exists over which the marginal beneficial effect of accumulating tacit AMK does not provide incremental benefits to the learning process, requiring alternative actions for performance to improve. Therefore, a first hypothesis is presented as follows, suggesting a curvilinear relationship:

H1: The relationship between reliance on tacit AMK and alliance performance follows an inverted U-shape.

\subsubsection{The pros and cons of relying on codified AMK}

The limitations of experiential learning urged researchers to focus on other sources of alliance capability development. Considering alliance management know-how as a dynamic capability, and alliances as heterogeneous, infrequent, and causally ambiguous events, some authors suggested that superior performance is likely to evolve not only from tacit accumulation of experience but also explicit knowledge articulation and codification (Zollo and Winter, 2002). Extending the work on codified knowledge in acquisitions (Zollo and Singh, 2004) to the field of strategic alliances, Kale and Singh (2007) argue that codification of accumulated alliance knowledge represents an important form of learning and might positively affect alliance capabilities and, thus, alliance outcomes.

Simonin (1997) argues that experience is only valuable when it is organized into specific know-how; prior work on the topic highlights the importance of making knowledge explicit to improve alliance success (Nonaka, 1994; Draulans et al., 2003). Particularly relevant has appeared to be the presence of codified knowledge in the form of, among the others, manuals, blueprints, and checklists. Indeed, the implementation of these tools can be beneficial to alliance performance for numerous reasons. To begin with, the institution of codified knowledge necessitates the articulation of prior experience embedded in individuals and, therefore, reduces the likelihood of losing it due to time deterioration, employees' turnover, and fragmented learning (Levinthal and March, 1993; Heimeriks and Duysters, 2007). Furthermore, dedicated artifacts can be easily reused and shared across the company, increasing the efficiency of alliance management and guiding the actions of inexperienced managers and partners. As a matter of fact, the presence of well-defined procedures and actions to be taken during the different phases of the alliance life cycle might guide the decision-making process, especially in conditions of high uncertainty due to unfamiliar and thorny issues. Finally, codification fosters alliance performance because managers are likely to sharpen their understanding of cause-effect relationships during the codification process itself, when they are compelled to draw consistent inferences from prior lessons and reflect on alliance experience (Nonaka, 1994; Zollo and Singh, 2004; Kale and Singh, 2007). Indeed, the codification process can be considered as a higher-order experiential learning where actors create mental maps regarding spatial, temporal, and causal relationships (Gavetti and Levinthal, 2000). Furthermore, the development of logically sound and effortful tools might go further the simple elaboration of causal relationships and patterns (double-loop learning), creating also a mechanism of triple-loop learning in which the several codification processes become opportunities to shape alliance knowledge and develop new sources of alliance capabilities development (Flood and Romm, 1996).

However, knowledge codification is also a double-edge mechanism (Heimeriks, 2010). Although it is likely to enhance alliance capabilities, an increasing level of codification can also trigger inertial behavior and rigidity, reducing time-efficiency and the number of opportunities considered, and, thus, negatively affecting alliance performance (Leonard-Barton, 1992; Heimeriks, 2010).

The main limitation of codification is that not all the nuances and richness of knowledge can be codified and redeployed. Indeed, there is a limit to the degree to which knowledge can be encoded due to its personal nature and situation specificity (Nonaka, 1994; Zander and Kogut, 1995). Moreover, the crisper understanding of the drivers of superior alliance performance developed during the codification process might involve only a restricted number of people within the company, if not supported by the creation of appropriate integration and diffusion mechanisms. The superior understanding of the action-performance linkages could even remain embedded in the minds of the individuals directly involved in the articulation and codification mechanisms, without the right incentives for deliberate learning (Zollo and Singh, 2004). Additionally, when firms rely only on standardized processes, they might reduce their ability to identify innovations and pursue improvements and, thus, reduce experimentation and exploration of new behaviors and patterns, which represent crucial aspects of alliance capability enhancement (Heimeriks, 2010). Therefore, an excessive use of standardized tools might be characterized by the fallacies of 
detachment, predetermination, and formalization (Mintzberg, 1994), which can lead to the reduction of the positive effects of codification. As in the case of tacit AMK, we consider, therefore, the positive effect of codified AMK, until the excessive accumulation of codified knowledge drives to detrimental effects on the marginal benefits of the learning process for successful alliances. The considerations mentioned above lead to a second hypothesis as follows, suggesting a curvilinear relationship:

H2: The relationship between reliance on codified $A M K$ and alliance performance follows an inverted U-shape.

\subsection{The moderating role of the DAF}

Heeding the call for a richer understanding of the antecedents of alliance success, many studies have moved away from internal processes aimed at deploying tacit and codified AMK. Recent research has turned its attention to alliance management structures (Draulans et al., 2003), as higher-order organizing mechanisms underlying the further enhancement of alliance capabilities and related performance (Kale et al., 2002; Rothaermel and Deeds, 2006; Kale and Singh, 2009).

DAFs are among the most debated of those higher-order mechanisms. The notion that this function plays an important role in building firm-level alliance capability is well established in the literature (Dyer et al., 2001; Kale et al., 2002; Draulans et al., 2003; Kale and Singh, 2007). Dyer et al. (2001, p. 38) describe the DAF as the function that "coordinates all alliance-related activity within the organization and is charged with institutionalizing processes and systems to teach, share, and leverage prior alliance-management experience and know-how within the company." Other definitions followed highlighting different aspects of the roles for the DAF. ${ }^{1}$

Despite heterogeneity in perspectives and focus, literature converges on defining the DAF as a formal organizational structure mandated with responsibility for: (i) storing lessons learned and best practices in alliance management with the aim to leverage on, develop, and disseminate alliance management know-how (Dyer et al., 2001; Kale et al., 2002); (ii) signaling firms' propensity and attitude toward alliance management with the aim to strengthen external and internal visibility, attractiveness, and legitimacy so that resource mobilization becomes easier (Draulans et al., 2003); (iii) coordinating, monitoring, and evaluating alliance-related processes along the entire alliance life cycle and across alliance portfolios with the aim to support knowledge transfer within and between organizations, as well as to take corrective actions when needed (Kale and Singh, 1999; Heimeriks et al., 2009).

Prior work has focused mainly on the direct effect of the presence of this function on alliance performance, neglecting the analysis of how it may affect the relationship between reliance on tacit and codified knowledge and alliance performance. Further, our knowledge of the key characteristics of a DAF is still limited (Kale and Singh, 2009), and additional research on the impact of these features on the relationship between AMK and alliance performance is needed.

\subsubsection{DAF, tacitness, and alliance performance}

As experiential learning increases leading to the accumulation of tacit AMK, the presence of the DAF has many roles to play in leveraging tacitness and improve alliance performance. First, the DAF is by definition an institutionalized locus of learning (Pisano, 1994) for assimilating, developing, and disseminating sticky lessons learned and best practices (Dyer et al., 2001; Draulans et al., 2003), on partner selection, negotiation, or governance structures. Accordingly, the DAF is likely to become the repository of alliance knowledge, accumulated through multiple relationships and usually dispersed among numerous managers. Indeed, the DAF becomes the focal point for learning and for leveraging lessons and feedbacks from prior and ongoing alliances.

Second, by forcing codification into fairly stable and repetitive patterns, the DAF facilitates replication, fosters the transfer of practices and tacit knowledge, and sets the basis for an alliance capability (Kale and Singh, 2009). In effect, it consistently establishes standardized procedures to articulate, document, codify, and share know-how about alliance management (Dyer et al., 2001). In so doing, it counters the natural tendency of benefits derived from experience to depreciate over time (Sampson, 2005), as well as the risk of losing important knowledge if those who possess it were to leave the organization (Kale et al., 2002; Kale and Singh, 2007).

1 Appendix A presents a review of the most recent contribution on the role of the DAF. 
Furthermore, by providing a legitimate place for the socialization of tacit knowledge, the DAF has the potential to at least partially overcome some of the barriers to tacit knowledge transfer (Szulanski, 1996). In fact, the exchange of knowledge, which is not codified due to high costs or non-codifiability (Zander and Kogut, 1995) and to its strong social component, is facilitated when formal structures are in place to promote and legitimate personal interaction (Levinthal and March, 1993; Nonaka, 1994; Heimeriks, 2010).

Finally, the DAF plays the crucial role of constantly monitoring and evaluating alliance performance (Kale et al., 2002; Draulans et al., 2003). This task is paramount for the deployment of tacit knowledge. In fact, it is necessary to increase the sense-making awareness about prior alliance outcomes and reveal relevant causes and contingencies (Zollo and Winter, 2002) to benefit from an improved alliance performance. When tacit knowledge prevails, causal ambiguity and unprovenness have a strong impact on reducing the ease of knowledge transfer and codification (Szulanski, 1996). Indeed, without a constant evaluation of the ongoing relationships and the debriefing of managers, it is more difficult to extrapolate valuable lessons from prior alliance experience, especially when knowledge remains not codified.

As a whole, the DAF facilitates alliance-related learning processes nurtured by experience and related tacit knowledge accumulation, thus leading to more effective management of future and ongoing alliance and turning into greater alliance success. In light of these arguments, we propose the following hypothesis:

H3: The presence of the DAF positively moderates the inverted U-shaped relationship between reliance on tacit AMK and alliance performance.

\subsubsection{DAF, codification, and alliance performance}

Besides acting as a facilitator in deploying tacit AMK, the DAF is conducive to better combinations of codified AMK (Nonaka, 1994).

As previously defined, codified knowledge is task-related knowledge in the form of objects or resources such as, for example, alliance guidelines or manuals conceived to help managers handle alliances over their entire life cycle. Yet, codification per se is a necessary but not sufficient condition for the development of firm-wide alliance management capabilities. On one side, more proactive and deliberate efforts are needed to translate mere documentation of alliance history into critical assessments and usable management tools (Zollo and Winter, 2002; Kale and Singh, 2007). On the other side, blueprints and rules of thumb could be routinely followed on a continuous basis without any deliberate effort to learn from them and adapt generalized AMK to partner-specific situations (Hoang and Rothaermel, 2005; Lavie et al., 2012). Given its critical role in supporting interaction and know-how sharing, the DAF enables those involved in managing alliances in turning artifacts into usable, useful management tools. Having such a function not only supports firms in the codification process of tacit knowledge into replicable practices but also in the identification and selection of the most suitable ones in given situations (Kale and Singh, 2007).

Additionally, having a centralized coordination of alliance-related tasks is beneficial for the correct exploitation of explicit AMK, in that it supports efficiency in knowledge search within the company. Especially as the number of alliances that firms manage simultaneously increases, it may be very difficult to use the right tools in the most appropriate context (Kale et al., 2002; Heimeriks et al., 2009). Accordingly, the presence of a specialized structure fosters the discovery and use of the most effective tools to manage the key phases of the alliance life cycle (Cohen and Bacdayan, 1994).

Finally, by providing strong incentives and motivations for alliance monitoring and metrics development, the DAF is fundamental to update and modify the tools that might be deployed to guide alliance management. Indeed, outdated and unquestioned artifacts might be detrimental because managers rely on them as the "last word" and may reduce future efforts to renovate alliance management practices (Leonard-Barton, 1992). Conversely, the continuous revision of the effectiveness of the artifacts is likely to improve alliance capabilities and, thus, enhance alliance performance. Therefore, these arguments lead to the following hypothesis:

H4: The presence of the DAF positively moderates the inverted U-shaped relationship between reliance on codified AMK and alliance performance. 


\subsection{DAF diversity, reliance on AMK, and alliance performance}

Building on empirical evidence showing organizational outcomes as a function of the characteristics of the teams involved (Hambrick and Mason, 1984), many studies are currently suggesting that the composition of the DAF is likely to play an important role in explaining its moderating impact on alliance performance (Dyer et al., 2001; Kale and Singh, 2009). Since investing in the creation of a DAF entails costs and efforts, a deeper understanding of how to configure it to benefit the most is a compelling question. Among the many facets that remain under-investigated, we decided to focus on how DAF diversity influences the relationship between reliance on tacit and codified AMK and alliance performance.

Hoang and Rothaermel (2005) suggest that alliance capability development is hampered by cognitive limitations. Indeed, considering the complex nature of alliances, managers face serious challenges when they try to draw valuable lessons from prior experience. As a consequence, DAF diversity has a role to play in countering both the risks of mistaken generalization of one alliance to the next (Haleblian and Finkelstein, 1999) and the likelihood of deploying written tools erroneously (Heimeriks, 2010).

Abundant theoretical and empirical evidence on the performance consequences of management team's composition has converged on demographic characteristics of teams' members as valid proxies of cognitive frameworks (Bantel and Jackson, 1989; Hambrick et al., 1996). Early team diversity research has focused on the performance consequences of know-how heterogeneity as resembled by past educational and life events, that is, educational diversity (Harrison and Klein, 2007). Accordingly, a more heterogeneous educational background is likely to favor the ability to address the numerous nuances of the alliance process more effectively and enhance the adaptability of the team to different circumstances. Moreover, pluralism in teams is likely to favor the scouting of divers alliance portfolios, thus turning into improved performance (Beckman et al., 2014).

Beyond know-how rooted into educational backgrounds, professional diversity, derived from distinct functional experiences (i.e., functional diversity), has emerged as a relevant predictor of teams' successful strategic choices (Buyl et al., 2011). Functionally diverse teams have a larger repertoire of skills and perspectives, as well as non-redundant peer networks. These attributes turn into easier access to unique information and improved decision-making.

Finally, tenure heterogeneity directly affects managers' experiences and perspectives, as well as their beliefs, increasing the cognitive diversity and improving the quality of decisions. In particular, different experience periods are important to guarantee different attitudes within the team (Nadolska and Barkema, 2014).

Based on existing literature, DAF diversity has a role to play in deploying both tacit and codified alliance knowledge. As far as tacit AMK is concerned, prior research suggests that firms can leverage prior experience when this is substantially heterogeneous. Van Knippenberg et al. (2004) suggest that heterogeneity is more likely to benefit performance when group task ability is higher; therefore, higher levels of DAF diversity are expected to foster learning processes (Jehn et al., 1999). Indeed, when reliance on tacit AMK is low, members' heterogeneity is likely to bring together diverse perspectives turning into improved decision-making (Mihalache et al., 2012). When the use of tacit AMK increases, heterogeneity is likely to increase the propensity for an extensive and meaningful confrontation of views, inhibiting superstitious learning (Zollo, 2009). Similarly, the presence of multiple perspectives, ideas, and capabilities reduces the risk of learning myopia and competence traps that are typical of extensive experiential learning (Levinthal and March, 1993; Levitt and March, 1988). Indeed, the likely presence of different experiences among the members of the unit increases the possibility of considering multiple opportunities instead of relying on a onedimensional, potentially fallacious experiential wisdom.

Thus, we hypothesize:

H5: DAF (i) educational, (ii) functional, and (iii) tenure diversity positively moderate the inverted U-shaped relationship between reliance on tacit $A M K$ and alliance performance.

DAF diversity can be expected to have an important role in the deployment of codified knowledge, too. Similarly to what happens in top management teams dealing with technology transfer (Knockaert et al., 2011) or innovation through offshoring (Mihalache et al., 2012), diversity supports the team in managing and coordinating dispersed knowledge, as well as in recognizing superior alternatives when dealing with new tasks (Simonin, 1997).

When codification increases, DAF diversity is likely to counter the risk for firms to remain stuck in their own routines. Instead, group variety enhances knowledge creation, information processing, and the development of new ideas, reducing the likelihood of inertial behavior (Nonaka, 1994; van der Vegt and Bunderson, 2005). As a matter 


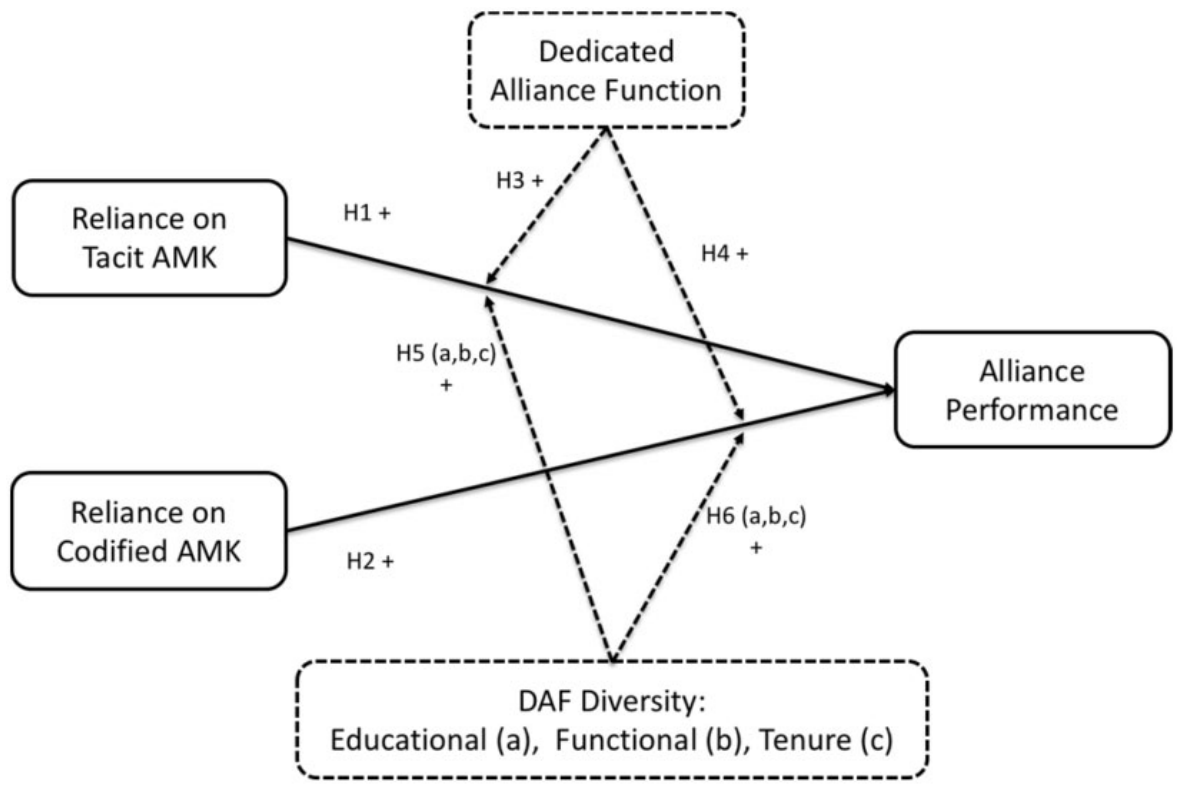

Figure 1. Theoretical framework.

of fact, many studies suggest that heterogeneous teams are more willing to pursue innovative strategies and to engage in change (Milliken and Martins, 1996). Conversely, a high level of homogeneity in the accumulated stock of prior experiences tends to favor complacency and excessive simplicity (Miller, 1999).

Thus, we hypothesize:

H6: DAF (i) educational, (ii) functional, and (iii) tenure diversity positively moderate the inverted U-shaped relationship between reliance on codified $A M K$ and alliance performance.

A representation of the theoretical framework of this study is presented in Figure 1.

\section{Methods}

\subsection{Sample and data collection}

To investigate the influence of relying on different types of AMK on alliance performance, as well as the moderating role of having the DAF with certain attributes, we focused on the firm as the unit of analysis and collected surveybased data.

Given the paucity of studies having analyzed the interaction between mechanisms to build firm-wide alliance capability, as well as boundary conditions making them effective, we were urged to select companies that repeatedly engaged in alliances, and which considered alliances as a key tool of their corporate strategy (Heimeriks et al., 2009). This sampling strategy was needed to maximize the chance to test and validate our hypotheses, in line with the objective of our research and to strengthen representativeness. In fact, according to prior research firms holding the abovementioned characteristics are more likely to present different levels of AMK, either tacit or codified, and might be more interested in deploying specialized structures to enhance their alliance performance (Kale et al., 2002).

We went through the following three-step process to select our sample. First, we started from those industries that, according to prior research, were consistently reporting higher propensity to ally. In line with previous studies, we identified computers, electronics, telecommunications, pharmaceuticals and biotechnologies, chemicals, machineries, transportation, and financial services as a set of industries where it was likely to observe expected patterns (Kale and Singh, 1999; Kale and Singh, 2007; Schilke and Goerzen, 2010). Industry categories were identified on the basis of three-digit Standard Industrial Classification (SIC) codes. Second, we selected large firms in each of the 
Table 1. Sample description

\begin{tabular}{|c|c|c|c|c|c|c|c|c|c|}
\hline & \multicolumn{3}{|c|}{ DAF } & \multicolumn{3}{|c|}{ DAF (\%) } & \multicolumn{3}{|c|}{ Ave. no. of previous alliances } \\
\hline & \multirow[b]{2}{*}{ No } & \multirow[b]{2}{*}{ Yes } & \multirow[b]{2}{*}{ Total } & \multirow[b]{2}{*}{ No } & \multirow[b]{2}{*}{ Yes } & \multirow[b]{2}{*}{ Total } & \multicolumn{3}{|l|}{ DAF } \\
\hline & & & & & & & No & Yes & Total \\
\hline \multicolumn{10}{|l|}{ Country } \\
\hline Northern Europe & 7 & 28 & 35 & 20 & 80 & 31 & & & \\
\hline Southern Europe & 27 & 20 & 47 & 57 & 43 & 42 & & & \\
\hline The United States & 4 & 15 & 19 & 21 & 79 & 17 & & & \\
\hline Other countries & 3 & 9 & 12 & 25 & 75 & 11 & & & \\
\hline \multicolumn{10}{|l|}{ Industry } \\
\hline Industrial & 20 & 24 & 44 & 45 & 55 & 39 & & & \\
\hline Service & 3 & 12 & 15 & 20 & 80 & 13 & & & \\
\hline IT & 5 & 24 & 29 & 17 & 83 & 26 & & & \\
\hline Other industries & 13 & 12 & 25 & 52 & 48 & 22 & & & \\
\hline \multicolumn{10}{|l|}{ Alliance experience } \\
\hline$>5$ & 12 & 15 & 27 & 44 & 56 & 24 & 36 & 45 & 81 \\
\hline $5-10$ & 20 & 13 & 33 & 61 & 39 & 29 & 160 & 104 & 264 \\
\hline $11-15$ & 5 & 13 & 18 & 28 & 72 & 16 & 65 & 169 & 234 \\
\hline $15-20$ & & 11 & 11 & 0 & 100 & 10 & 0 & 198 & 198 \\
\hline$<20$ & 4 & 20 & 24 & 17 & 83 & 21 & 100 & 500 & 600 \\
\hline \multicolumn{10}{|l|}{ Reliance on AMK } \\
\hline Tacit $<$ average & 15 & 24 & 39 & 38 & 62 & 35 & & & \\
\hline Tacit $>$ average & 26 & 48 & 74 & 35 & 65 & 65 & & & \\
\hline Codified $<$ average & 14 & 18 & 32 & 44 & 56 & 28 & & & \\
\hline Codified $>$ average & 27 & 54 & 81 & 33 & 67 & 72 & & & \\
\hline
\end{tabular}

industry categories listed above, which reached more than $€ 70$ million (approximately $\$ 100$ million) in annual revenues and had more than 100 employees in 2015. Consistently with prior studies on alliance capability (Kale and Singh, 2007; Schilke and Goerzen, 2010), large firms are usually engaged in a significantly greater number of relationships than small firms (Hagedoorn and Schakenraad, 1994). These thresholds have been considered relevant, as they represent a valuable proxy of firms' managerial and financial resource endowments. Companies were identified through Orbis database, using appropriate filters for industry categories, size, and revenue classes. Third, we looked for contact information on a senior executive who might be in charge of or involved in the firm's alliance activities. In line with existing studies, top executives represented the most qualified respondents, due to the strategic nature of the content and the cross-corporate issues involved in alliances (Eisenhardt and Schoonhoven, 1996). Moreover, we focused on executives in charge of the corporate development, corporate planning, and alliance or merger \& acquisition (M\&A) department. These managers not only were likely to be more informed about alliance practices but also had more interest in the completion of the questionnaire (Kale and Singh, 1999). In case this role was missing within the company's organization chart, the survey was directly sent to the CEO or a member of the Board of Directors, who have been also considered appropriate respondents in prior alliance studies (Simonin, 1997; Draulans et al., 2003). To access the appropriate contact person within the organization, a combination of secondary data provided by Zephyr and Thomson One Banker databases, as well as social media (e.g., ASAP group) was used. In some cases, a direct contact with the company or the review of its website allowed the identification of the key informant or the obtainment of the necessary contact.

An initial sample of 1150 e-mail contacts was created, and hence, an e-mail questionnaire was sent in 2015 to managers' personal e-mail addresses by using a two-wave (e)mailing approach, with a reminder after a time lapse of 10 days, which underlined the relevance of the study and acknowledged the receivers that the questionnaire was not an unsolicited e-mail (see Appendix B for the structure of the survey). After the two rounds, we received 120 responses, of which 113 were complete (corresponding to an overall response rate of about 10\%), each corresponding to a single-firm in the sample. Furthermore, the $63 \%$ of the responding firms had a dedicated unit to 
manage alliances; on average these structures involved six to eight people and were in place for 7-8 years. Details on the distribution of the sample are reported in Table 1.

Though sample size is relatively small, it is aligned with highly cited research based on primary data collection on the performance consequences of firm-wide alliance capability (Kale et al., 2002; Kale and Singh, 2007; Heimeriks et al., 2009; Nielsen and Nielsen, 2009).

Furthermore, to verify the quality of the data, we performed two sets of data analysis. First, we checked the presence of common method bias, which is typical of self-administered surveys and can result in measurement errors (Podsakoff and Organ, 1986; Podsakoff et al., 2003). Accordingly, the Harman's one factor test was conducted. All the items associated with tacit and codified AMK and alliance performance were entered into an exploratory factor analysis, using an unrotated principal components factor analysis, a principal component analysis with varimax rotation, and a principal axis analysis with varimax rotation. This procedure allowed determining how many factors were necessary to account for the variance in the variables, and testing if one general factor accounted for the majority of the covariance among the variables (Podsakoff et al., 2003). All the three analyses revealed the presence of three distinct factors with eigenvalues greater than 1, rather than a single major one. The three factors together accounted for $60.5 \%$ of the total variance in the principal component factor analysis and $69.48 \%$ in the principal axis analysis, while the first and largest factor did not account for the majority of the variance $(41.87 \%$ and $44.69 \%$, respectively, in the principal component and principal axis analysis). Thus, no general factor was apparent in the data collected, suggesting that common method bias was not of great concern and, thus, unlikely to affect the interpretation of the results for this research.

Second, we performed an assessment of potential non-response bias, by identifying possible differences between early and late respondents, under the assumption that late respondents are similar to non-respondent than early respondents are to non-respondents (Klijn et al., 2013). Two-sample $t$-tests for these classes of respondents suggested that no significant differences existed with respect to alliance experience $(t=0.31$, n.s.), age $(t=0.48$, n.s.), and size $(t=0.40$, n.s.). Thus, these tests do not provide evidence that the data are subject to non-response bias.

\subsection{Operationalization of key variables}

\subsubsection{Dependent variable: alliance performance}

Despite having been included in many alliance studies, alliance performance has not a single measurement approach. On one side, studies have focused on financial gains associated to performance, such as, for example, profits, sales, or abnormal stock market returns after announcements of alliances (Anand and Khanna, 2000; Rocha-Goncalves and Gonçalves, 2011). Yet, most alliances do not report financial performance, which has been proved in any case to be biased by partners' accounting preferences (Krishnan et al., 2006). In an attempt to overcome the limits of financial measures in providing consistent and uniform ways of measuring performance across large, heterogeneous and multi-geography samples (Gulati, 1999), a second measurement approach has emerged based on managers' evaluation of the extent to which the competitive position of the firm has improved as a result of the alliances performed in a given time frame, or the extent to which the firm has acquired skills from alliance partners, thus considering alliances successful (Draulans et al., 2003; Heimeriks and Duysters, 2007). The superiority of managerial evaluation over financial returns has been further corroborated by Geringer and Hebert (1991), who demonstrated a high level of correlation between managerial assessments and accounting and financial measures. This confirms the robustness of the former compared to the latter.

Instead of relying on single-item evaluations of alliance performance focused on specific issues (e.g., the extent to which an alliance has contributed to competitive advantage of the core firm), research has demonstrated the superiority of multi-item scales of performance in disentangling the multifaceted nature of alliance performance (Kale and Singh, 2007).

Therefore, we decided to estimate the overall firm's alliance performance based on respondents' self-assessment. Therefore, we first adapted the five-item measure of alliance performance from Kale and Singh (2007). Accordingly, we included assessments referred to the quality of the relationships, the degree of goals fulfillment, the impact on competitive position and skill enhancement, and overall assessment of alliance success. We then added an additional item, that is, the extent to which respondents perceived the allies to be satisfied with the focal organization as a good partner. Even if based on perceptions, bringing in perspectives of other partners involved has emerged as enriching 
the robustness of self-evaluated performance (Krishnan et al., 2006). We also reverse-coded one of the items to control and limit the response pattern bias. Respondents used a simple seven-point Likert scale to give their level of agreement/disagreement on the six items (Dyer et al., 2001; Kale and Singh, 2007), explicitly referred to alliances completed over the previous 3 years, namely, between 2012 and 2014. With a Cronbach's alpha of 0.89, the performance scale demonstrated high reliability.

The firm-specific values of the dependent variable resulted from an exploratory factor analysis. The appropriateness of the resulting construct was supported by the results of the KMO and Bartlett's sphericity tests. Indeed, the KMO coefficient was above the common threshold of 0.7 and the Bartlett's test highly significant, supporting the construct's robustness. Moreover, considering the presence of only one factor, we verified if the results of the factor analysis significantly differed from the mean of the items. This was not the case supporting the robustness of the final measure built through the factor analysis (please, see Appendix B for factor analysis details).

\subsubsection{Independent variables: reliance on tacit and codified AMK}

The predictors of the analysis, namely, reliance on tacit and codified AMK, have been measured through the combination of several items. A four-item measure was created for reliance on tacit AMK, adapting the knowledge sharing scale developed by Dyer et al. (2001) and Kale and Singh (2007) on experiential alliance knowledge. Reliance on tacit AMK referred to the degree to which managers share and use tacit know-how and lessons learned by doing within the firm through formal and informal communities, personnel rotations, and other knowledge-sharing activities.

Reliance on codified AMK was measured using the four-item scale of alliance knowledge codification developed by Kale and Singh (2007) and adapted from the study by Zollo and Singh (2004). Respondents were asked to assess their agreement/disagreement on the following aspects of codification: the extent to which alliance know-how was articulated and formalized in specific tools and how these tools were deployed in alliance management processes.

Both for tacit and codified AMK, respondents were explicitly asked to rate their agreement/disagreement with the statements in the questionnaire on a seven-point Likert scale and refer to alliances managed over the previous 3-year period (i.e., between 2012 and 2014).

Consistently with the procedure followed for the dependent variable, we therefore run an exploratory factor analysis related to the two constructs, to test their validity and reliability. First, we identified the presence of items that correlated weakly with the related construct, and, second, we investigated redundancy or duplication between items. For the purpose of this test, an item-total correlation below 0.40 represented an item with a poor relationship with the underlying construct. Conversely, an item-total correlation greater than 0.90 suggested the presence of redundancy and duplication. The results showed that only one element (Factor 1 in the reliance on tacit knowledge construct, referred to whether alliance managers relied on prior experience to guide the formation or management of alliances) was not in the acceptable range and, thus, dropped from the analysis. The reason for exclusion is probably due to the fact that relying on previous experience cannot be exclusively related to a specific type of AMK. Overall, the results of the item-total correlation tests strongly supported the assumption of items and constructs validity. Cronbach's alpha coefficients have been computed for each variable (Cronbach's alpha for tacit AMK $=0.71$; Cronbach's alpha for codified AMK $=0.90$ ). All the calculated alphas were above the threshold of 0.70 (Nunnally, 1970 ) and none of them could be improved eliminating one of the items, confirming the strong reliability of the constructs elaborated. Furthermore, the appropriateness of the resulting construct was supported by the results of the $\mathrm{KMO}$ and Bartlett's sphericity tests. Indeed, the KMO coefficient was aligned to the common threshold of 0.7 and the Bartlett's test highly significant, supporting the construct's robustness analysis (see Appendix B for factor analysis details).

\subsubsection{Moderating factors}

Dedicated alliance function: The presence of the DAF was assessed using a dummy variable (Kale and Singh, 2007; Heimeriks et al., 2009). Firms reporting to have the DAF were therefore coded as 1, 0 otherwise.

DAF diversity: To assess the diversity of the members of the DAF, multiple questions on the background and experience of the managers have been posed in three different sections of the questionnaire. The degree of diversity was calculated through the Blau's index, which is a generally accepted measure of heterogeneity in a management team (Finkelstein and Hambrick, 1996). This index was computed as $1\left(P_{i}\right) 2$, where $P_{i}$ is the percentage of individuals in the ith category, respectively, educational, functional, and tenure diversity; therefore, the higher is the resulting score, 
the greater the heterogeneity on a specific dimension. In this case, we deployed a 0-100 scale, to increase the differentiation with the firms without the DAF. Considering the above three $i$ categories used in this study, respondents were asked to assess educational diversity by reporting the percent distribution of the different educational backgrounds (business, engineering, law, etc.) across the team members. Similarly, functional diversity has been calculated considering the percentage of members with experience in a specific organizational function $(R \& D$, finance, business management, etc.). Finally, tenure diversity has been based on the percent distribution across different years of experience of the members within the DAF of the focal firm.

\subsubsection{Controls}

Several controls were included in the analysis to account for both exogenous influences on alliance performance and unobserved individual heterogeneity. To control for country effects and industry effects, we included a full set of dummies, one for each country and sector. Specifically, countries included in the sample aggregated into four categories: Northern Europe, Southern Europe, the United States, and other countries. Industry effects referred to the sector mentioned above in the sample selection section, and further aggregated into the four categories, that is, industrials, service, IT, and other industries. Prior research has suggested that larger firms are more likely to enter into alliance relationships than smaller firms (Hagedoorn and Schakenraad, 1994; Dickson and Weaver, 1997). We therefore, controlled for firm size as reported by respondents in the survey. Similarly, we controlled for firm age to account for potential inertial forces based on experience (Kelly and Amburgey, 1991). Both firm size and age were referred to the year before the survey was completed, i.e., 2015. Respondents were asked to report on their age and size across four categories (e.g., less than 5 years for age and less than 200 employees for size). We then substituted the category means (e.g., between 200 and 500 becomes 350) for our subsequent analysis.

Prior research has pointed out to the relevance of alliance experience in explaining alliance performance (Anand and Khanna, 2000). Hence, we controlled for this variable asking respondents to report the number of signed alliances over the 5-year period preceding the time frame for performance assessment (i.e., between 2008 and 2012). A 5 -year period is a generally accepted time frame to examine the contribution of alliance experience on alliance performance (Kale et al., 2002; Zollo et al., 2002). Given our research design, we cannot fully account for inter-temporal learning effects, which could have affected later performance assessment. Yet, we attempted to at least partially lag alliance experience and alliance success by referring the two variables to different time windows. As for age and size, respondents self-selected their position across five alliance experience's classes. We than substituted the category means for subsequent analysis.

The reliance on self-assessed performance measures could be biased by unobserved characteristics of the respondents, as well as the role played by the focal organization in the alliance or the context in which alliances took place. Alliance types, partner composition, and embeddedness into contexts have proved to be significant in affecting alliance behavior and related performance (Krishnan et al., 2006; Rothaermel and Deeds, 2006; Hottenrott and LopesBento, 2015; Niesten and Jolink, 2015). Large evidence exists on the influence of national culture on people's value and perceptions, decision-making, strategy formulation, and inter-firm cooperation (Child and Faulkner, 1998). Consistently with previous research, we controlled for the two most significant dimensions of national culture as developed by Hofstede (1991) in predicting firm behavior and organization, that is, uncertainty avoidance and power distance (Golonka and Rzadca, 2013). To account for context-related factors potentially affecting alliance propensity and perceived performance (Rowley et al., 2000), we controlled for regulatory quality and rule of law countryindexes (Kaufmann et al., 2011). Such indicators are reflexive of country-specific risks that have emerged as influencing firm ability to benefit from alliances (Nielsen, 2007). In fact, political instability and lack of adequate regulatory infrastructure increase uncertainty with respect to property rights or legitimate returns, thus turning into lower alliance performance because of the need to incur into additional transactional and information processing costs along the whole alliance life cycle.

Finally, since both tacit and codified AMK are expected to have an impact on alliance performance, they are consistently and alternatively included in all the regression models as controls.

\subsection{Data analysis}

Although continuous, our measure of alliance performance has boundaries by construction. In fact, it cannot take values less than 0 , as well as it is right-censored, with three firms reporting the highest possible value across all items 
of the alliance performance scale. Thus, we used Tobit regression analysis as an appropriate form of regression when the dependent variable is censored (Maddala, 1983). Having analyzed the sample to test for normality and linearity, we discovered that our dependent variable had a significant skewness of $-1.35(P<0.000)$ and slightly significant excess kurtosis of $1.46(P<0.05)$. As we were concerned with normality, we relaxed the homoscedasticity assumption, thus performing robust standard error estimation. This was confirmed by predicting residuals of ordinary least square estimations and testing for normality. They resulted non-normally distributed with skewness of -1.38 $(P<0.000)$ and kurtosis of $6.87(P<0.05)$.

To test curvilinear hypotheses, we squared tacit and codified AMK and entered them in the regression together with the linear effect.

To test interaction effects, we standardized the key variables prior to forming interaction terms (Jaccard and Turrisi, 2003). We used a hierarchical regression approach to test our hypotheses, including the control variables first, and then the predictors and moderating effects.

\section{Results}

\subsection{Sample characteristics and correlations}

Tables 1 and 2 show, respectively, the sample description and the descriptive statistics. About $64 \%$ of the firms in the sample have the DAF. On average, a firm in the sample had perceived its alliance performance as moderately successful during the period 2012-2014. The average score of reliance on tacit AMK to manage alliances is 4.61, which is placed in between slightly and moderate agreement. The average score of reliance on codified AMK is slightly lower than the level of agreement on the use of tacit AMK, and equal to 4.03. Among firms with the DAF, $65 \%$ of the sample relied more on tacit AMK than the average. Similarly, $67 \%$ of the firms relied more on codified AMK than the average. Approximately $29 \%$ of the firms had completed between 5 and 10 alliances during the period 2008-2012. The cumulated alliance experience of the firms in the sample is roughly 600 alliances. Firms with the DAF account for the majority of completed alliances.

On average, firms in the sample have 787 employees. The average age is equal to 25 years. As for the DAF composition, functional diversity is approximately higher than educational and tenure diversity, with an average score of 37.52 .

The cross-correlation between the key variables is as expected. The results show that all the explanatory variables, including the moderating ones, have a positive and significant relationship with alliance performance. In particular, reliance on tacit AMK has the highest correlate $(r=0.48 ; P<0.01)$ with alliance performance. In line with previous literature, size, age, and alliance experience strongly correlate with alliance performance. Having the DAF has a positive, significant correlation with perceived alliance performance. The same holds for diversity across the three attributes.

\subsection{Modeling and hypotheses testing}

Next, the regression results of the impact of reliance on tacit and codified AMK on alliance performance are presented. The first model in Table 3 includes the direct effects of reliance on tacit and codified AMK and all control variables. In line with previous work, the effect parameters of tacit and codified AMK were positive and strongly significant (respectively, $r=0.31$ with $P<0.01$ and $r=0.21$ with $P<0.01$ ). It implies that after including all the control variables, the higher the reliance on both types of AMK, the larger the perceived alliance performance. It was also confirmed that firm size and previous alliance experience are positively associated with alliance performance. Age has a negative and significant association with alliance experience, suggesting that older firms are less likely to extract benefits from completed alliances. The effect of level of regulatory quality was also positive $(r=0.23)$ but only marginally significant $(P<0.10)$. No effect of the other context-related indicators was found.

Model 2 added the squared terms of reliance on tacit and codified AMK. This model tested our first two hypotheses that the positive relationships between reliance on both knowledge types and alliance performance decreases or even turns negative for high levels of knowledge use. Reliance on tacit AMK and its squared value are both statistically significant. First, reliance on tacit AMK enters positively $(r=0.43, P<0.05)$. The negative, significant sign on the second-order term $(r=-0.27, P<0.05)$ suggests that $H 1$ is supported. The same holds for reliance on codified AMK. The direct effect and the second-order effect are both marginally significant with the expected signs. In fact, 


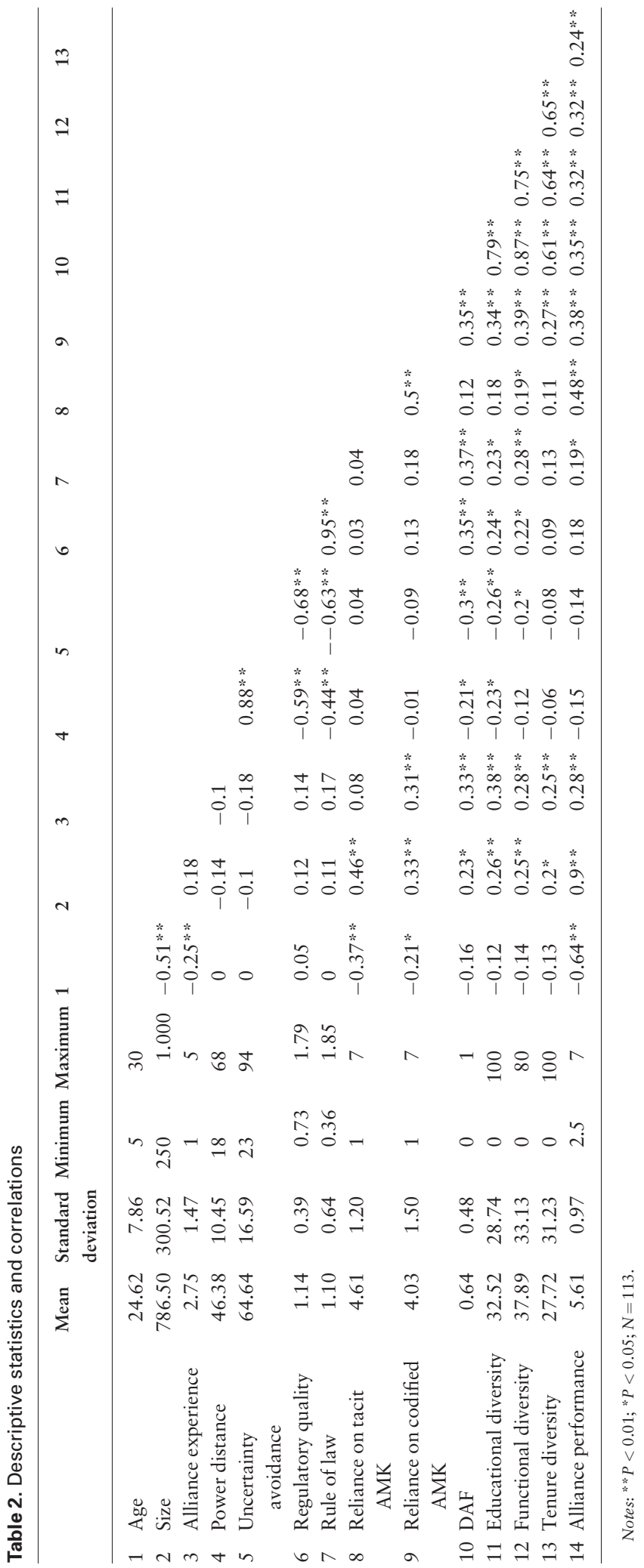



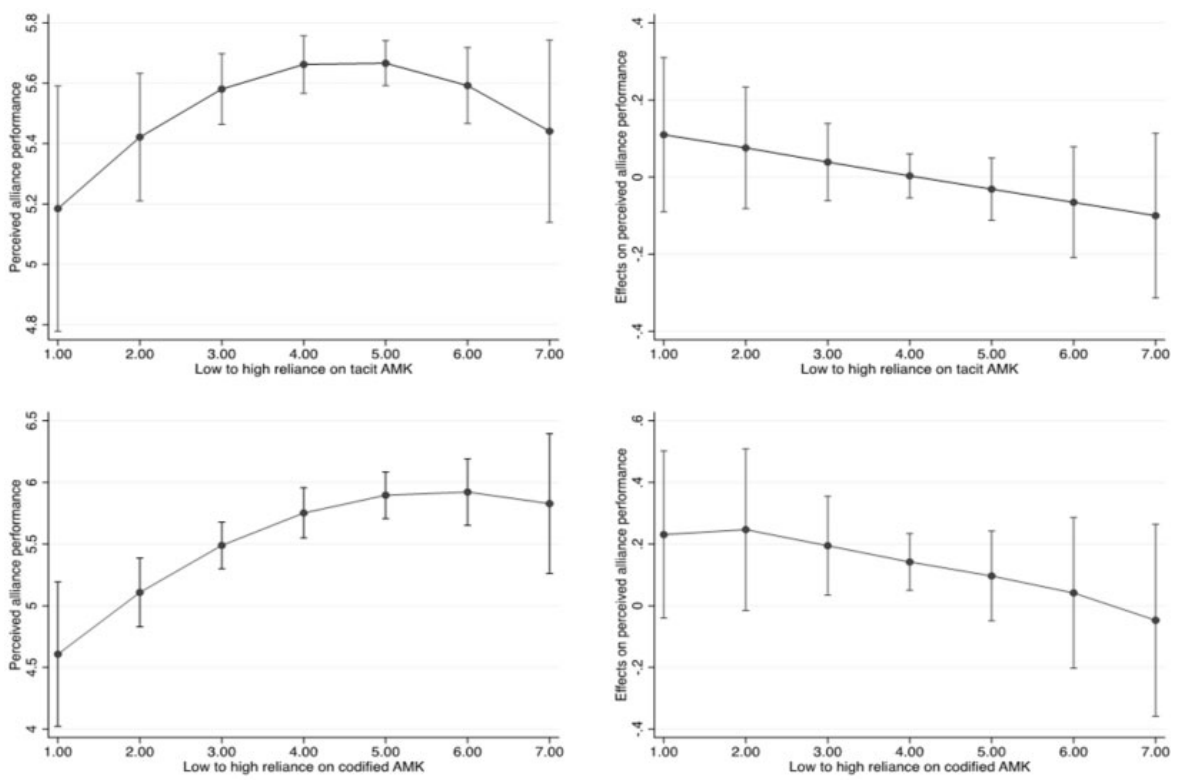

Figure 2. Predictive margins and average marginal effects of reliance on AMK on alliance performance (Model 2; 95\% confidence intervals).

reliance on codified AMK has a positive direct impact on alliance performance $(r=0.26, P<0.10)$. Yet, high levels of reliance on this knowledge type turns into decreased performance $(r=-0.03, P<0.05)$. Accordingly, $H 2$ found marginal statistical support.

To further confirm the hypothesized U-shaped relationships between reliance on tacit and codified AMK and alliance performance, we performed the U-test suggested by Lind and Mehlum (2010). In particular, we tested for the slope of the curve at several points in a linear ordinary least squares model. Both for tacit and codified AMK, the estimated maximum is well within the data range (respectively, 4.55 and 4.23). Moreover, the $t$-statistics for lower and upper bound are significant, thus supporting the hypotheses of an inverted U-shape for both knowledge types. ${ }^{2}$

To gain more insights into the magnitude of the effects, we calculated the marginal predictions and average marginal effects of our explanatory variables on alliance performance at different values of the distribution of both reliance on tacit AMK and use of codification (Greene, 2010). The results are graphically reported in Figure 2.

The left-hand side shows the predictive margins and the right-hand side the average marginal effects over the range of possible levels of reliance on tacit and codified AMK. As for tacit AMK, it increasingly improves alliance performance in the range between strong disagreement and slight agreement of firms' reliance on tacitness to manage alliances. The impact of reliance on tacit AMK turns negative when managers declare to moderately and strongly rely on tacitness. The right-hand side shows the derivative, that is, the slope of the predictive margins curve. It indicates the magnitude of the impact of a marginal increase in reliance on tacit AMK on the outcome variable. It is clear that the returns to increasing reliance on tacitness are decreasing and turns negative around 4.00, which corresponds to a slight agreement on the company reliance on this type of knowledge.

2 For reliance on tacit AMK, the $t$-values are equal to 2.08 for the lower bound $(P<0.05)$ and -1.60 for the upper bound $(P<0.05)$. The overall test of presence of an inverted $\mathrm{U}$-shape rejects the null hypotheses with t-value equal to $1.60(P$ $<0.05)$. As for reliance on codified AMK, the $t$-values are equal to 1.54 for the lower bound $(P<0.05)$ and -1.50 for the upper bound $(P<0.05)$. The overall test of presence of an inverted $\mathrm{U}$-shape rejects the null hypotheses with $\mathrm{t}$-value equal to $1.49(P<0.05)$. 
Table 3. Tobit regression models of alliance performance

\begin{tabular}{|c|c|c|c|c|c|c|c|c|}
\hline & \multicolumn{2}{|l|}{ Model 1} & \multicolumn{2}{|l|}{ Model 2} & \multicolumn{2}{|l|}{ Model 3} & \multicolumn{2}{|l|}{ Model 4} \\
\hline & Coefficient & S.E. & Coefficient & S.E. & Coefficient & S.E. & Coefficient & S.E. \\
\hline Cons & $0.04 *$ & 2.010 & $4.35 * *$ & 0.550 & $2.13 * *$ & 1.865 & $3.88 * *$ & 3.466 \\
\hline Age & $-0.26^{* *}$ & 0.050 & $-0.52 * *$ & 0.087 & $-0.23 * *$ & 0.052 & 0.06 & 0.072 \\
\hline Size & $0.66 * *$ & 0.040 & $0.00 * *$ & 0.051 & $0.68 * *$ & 0.050 & $-0.14 *$ & 0.063 \\
\hline Previous alliance experience & $0.14 * *$ & 0.047 & $0.08 * *$ & 0.025 & $0.05 *$ & 0.024 & $0.12 * *$ & 0.049 \\
\hline Power distance & 0.01 & 0.057 & 0.00 & 0.005 & 0.03 & 0.069 & -0.10 & 0.123 \\
\hline Uncertainty avoidance & 0.00 & 0.031 & -0.02 & 0.036 & -0.02 & 0.036 & 0.05 & 0.065 \\
\hline Regulatory quality & 0.04 & 1.591 & $0.24^{\dagger}$ & 0.139 & 0.69 & 1.552 & -3.14 & 2.917 \\
\hline Rule of law & $2.13 *$ & 0.891 & -0.81 & 0.682 & -0.83 & 0.901 & $2.68^{\dagger}$ & 1.968 \\
\hline Tacit AMK & $0.31 * *$ & 0.079 & $0.43^{*}$ & 0.219 & $0.64 *$ & 0.266 & $0.34 * *$ & 0.080 \\
\hline Codified AMK & $0.21 * *$ & 0.052 & $0.26^{\dagger}$ & 0.159 & 0.08 & 0.205 & $1.66^{* *}$ & 0.420 \\
\hline$(\text { Tacit AMK })^{2}$ & & & $-0.37^{*}$ & 0.209 & $-0.07^{*}$ & 0.033 & -0.05 & 0.058 \\
\hline$(\text { Codified AMK) })^{2}$ & & & $-0.03^{\dagger}$ & 0.02 & -0.15 & 0.189 & $-0,17^{* *}$ & 0.055 \\
\hline DAF & & & & & $2.11 * *$ & 0.684 & $4.50 * *$ & 1.037 \\
\hline Tacit AMK*DAF & & & & & $-0.78 *$ & 0.342 & & \\
\hline$(\text { Tacit AMK })^{2 *}$ DAF & & & & & $0.08^{\dagger}$ & 0.041 & & \\
\hline Codified AMK* DAF & & & & & & & $-2.10 * *$ & 0.555 \\
\hline$(\text { Codified AMK })^{2 *}$ DAF & & & & & & & $0.23 * *$ & 0.070 \\
\hline \multicolumn{9}{|l|}{ Model fit } \\
\hline Observations & 113 & & 113 & & 113 & & 113 & \\
\hline Left-censored & 1 & & 1 & & 1 & & 1 & \\
\hline Right-censored & 3 & & 3 & & 3 & & 3 & \\
\hline Pseudo $R^{2}$ & $0.262 * *$ & & $0.220 * *$ & & $0.358 * *$ & & $0.308 * *$ & \\
\hline Log likelihood & -118.01 & & -44.82 & & -22.69 & & -110.66 & \\
\hline
\end{tabular}

Notes: Industry and geographic dummies included, not presented. $\quad{ }^{*} P<0.01 ; \quad{ }^{*} P<0.05 ; \quad{ }^{\dagger} P<0.10$.

A similar pattern emerges for reliance on codified AMK. Different from tacit AMK, the impact of reliance on codification starts decreasing when the explanatory variable reaches a value around 6.00, which correspond to a moderate agreement with the firm's reliance on codification. The average marginal effects for codification are slightly different from those related to reliance on tacitness. In fact, returns are first increasing. Then, they decrease around 2.00 and turn negative for values of the explanatory variable around 6.50. It means that higher levels of reliance on codified AMK benefit alliance performance more than higher levels of reliance on tacit AMK.

Model 3 in Table 3 then tested the moderating role of having the DAF on the U-shaped relationship between reliance on tacit AMK and alliance performance. Results shows that the direct effect of having the DAF is positive and significant $(r=2.11, P<0.01)$, thus confirming empirical findings on the beneficial impact of the DAF on alliance performance. More importantly, both the interaction with the linear term and the squared term are significant (respectively, $r=-0.78, P<0.05 ; r=0.08, P<0.10$ ), thus marginally supporting H3. Similarly, Model 4 tested the moderating role of the DAF on the curvilinear relationships between reliance on codified AMK and alliance performance. The direct effect of having the DAF remains positive and significant $(r=4.50, P<0.01)$. The linear interaction and the quadratic interaction are significant and of the expected signs (respectively, $r=-2.10, P<0.01 ; r=0.23, P<0.01$ ). The interaction effects confirm our $\mathrm{H} 4$, suggesting that the DAF reduces the negative impact of increasing levels of reliance on codified AMK.

Figure 3 shows these contingency effects and reports the predictive margins of reliance on both tacit and codified AMK on alliance performance for firms with or without the DAF.

For firms with the DAF, alliance performance is higher at low levels of reliance on tacit AMK. It then decreases until it stabilizes at higher levels compared to those of firms without the DAF. This effect is more pronounced in the case of codified AMK. The right-hand side of the figure shows that the U-shape is positive for 

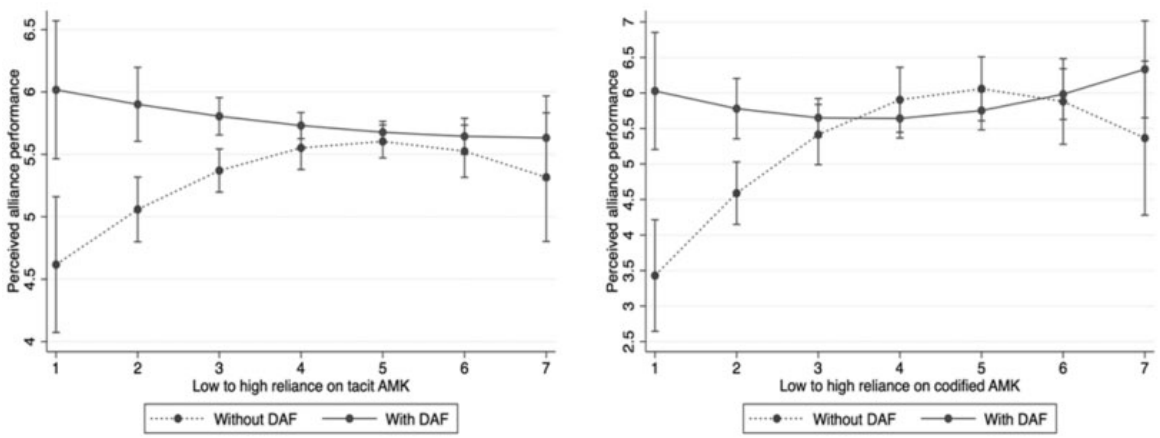

Figure 3. Predictive margins of reliance on AMK on alliance performance by DAF (Models 3 and $4 ; 95 \%$ confidence intervals).

firms with the DAF. In fact, at low and high levels of reliance on codified AMK, the DAF leads to higher alliance performance. The DAF has a detrimental role for alliance performance in those firms with a moderate reliance on codified AMK.

To go deeper into the investigation of how the DAF moderates the inverted U-shaped relationship between reliance on tacit and codified AMK and alliance performance, our last set of hypotheses introduced the moderating role of DAF diversity across three attributes, that is, educational, functional, and tenure diversity.

Models 5-7 in Table 4 show the results of the interaction between the three DAF attributes and the linear and squared terms for reliance on tacit AMK. All the attributes have a negative, significant impact when interacted with the linear term $(r=-0.02, P<0.01$ for educational diversity; $r=-0.48, P<0.05$ for functional diversity; $r=$ $-0.03, P<0.01$ for tenure diversity), and a positive, significant impact on alliance performance when interacted with the squared term $(r=0.01, P<0.01$ for educational diversity; $r=0.38, P<0.10$ for functional diversity; $r=0.01, P<0.05$ for tenure diversity). Results confirm our $H 5$, pointing out the beneficial impact of DAF diversity on the ability of firms to exploit tacit AMK. To make use of tacit AMK, educational diversity emerges as the most effective moderator.

A similar, yet more significant, pattern emerges with the regard to the moderating effect of DAF diversity on the curvilinear relationship between reliance on codified AMK and alliance performance. Results are reported in Models $8-10$, where the three linear interactions are negative and significant, and the quadratic interactions are positive and significant (respectively, $r=1.27, P<0.01$ for educational diversity; $r=0.01, P<0.01$ for functional diversity; $r=0.03, P<0.01$ for tenure diversity). Results confirm our H6, showing the beneficial impact of DAF diversity on the ability of firms to exploit codified AMK.

Figure 4 depicts how DAF diversity moderates the nonlinear relationships between reliance on tacit and codified AMK and alliance performance. The graphs present the predictive margins of reliance on AMK on alliance performance by the three DAF attributes. We considered 1 standard deviation below and above the mean to represent the low and high values of DAF educational, functional, and tenure diversity.

The left-hand side reports the predictive margins of reliance on tacit AMK on alliance performance by DAF educational, functional, and tenure diversity, while the right-hand side shows the predictive margins of reliance on codified AMK.

Similar patterns emerge across the different DAF attributes. The graphs indicate an inverted U-shape for average values of reliance on both types of knowledge. For firms DAF diversity that is 1 standard deviation above the mean, the U-shape is positive, meaning that those firms relying on low and high levels of both knowledge types experience improved alliance performance when their DAF is also diverse. For firms with DAF diversity, that is, 1 standard deviation below the mean, the opposite effect holds. The U-shape is inverted and the slope is more negative than for firms with average levels of DAF diversity. These effects amount to the moderation effect we predicted in $H 5$ and H6. The positive U-shape is more pronounced when reliance on codified AMK combines with highly diverse DAFs. Instead, DAF diversity is more relevant for firms with low levels of reliance on tacit AMK than for high level of tacitness use. 


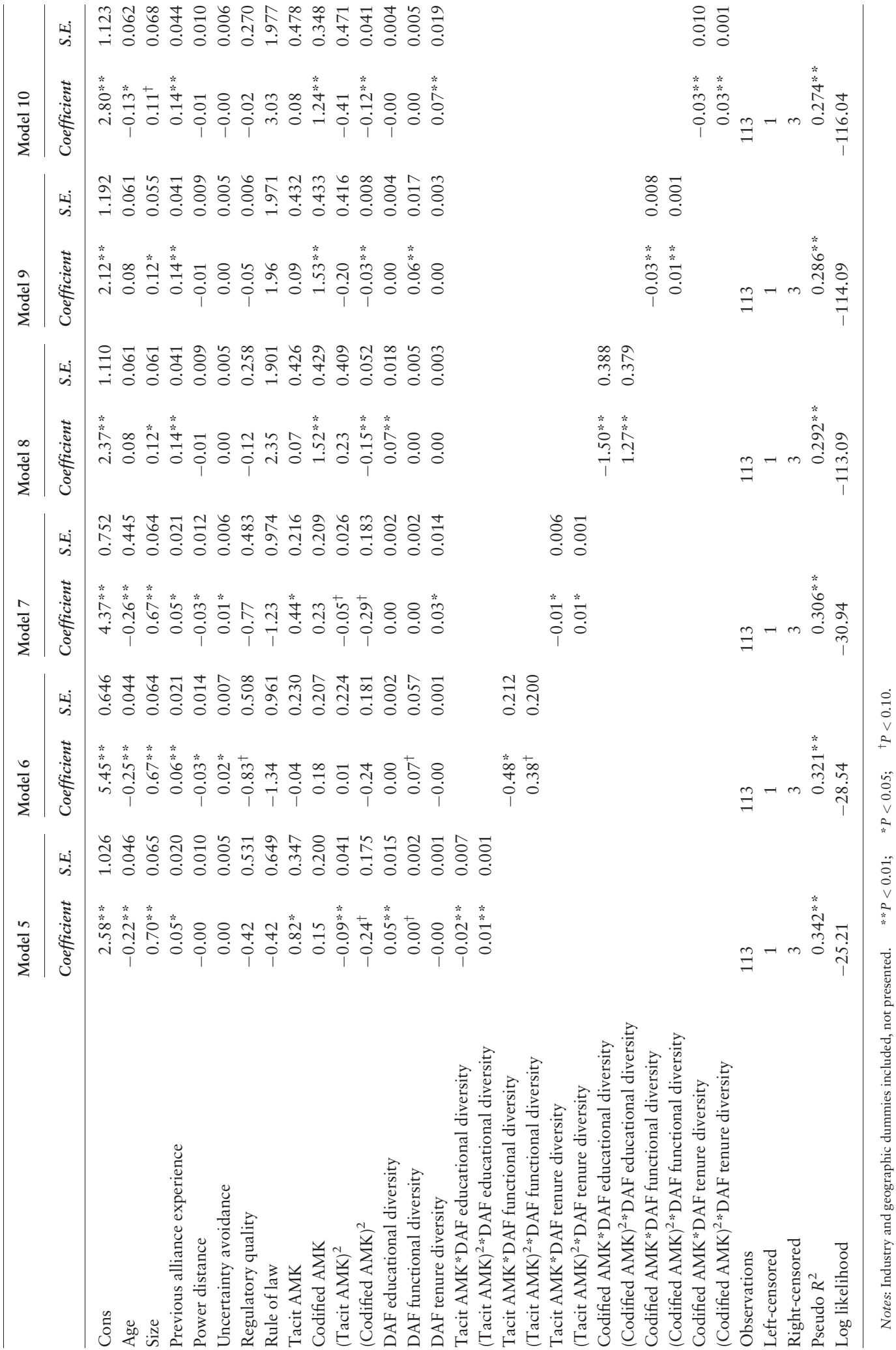



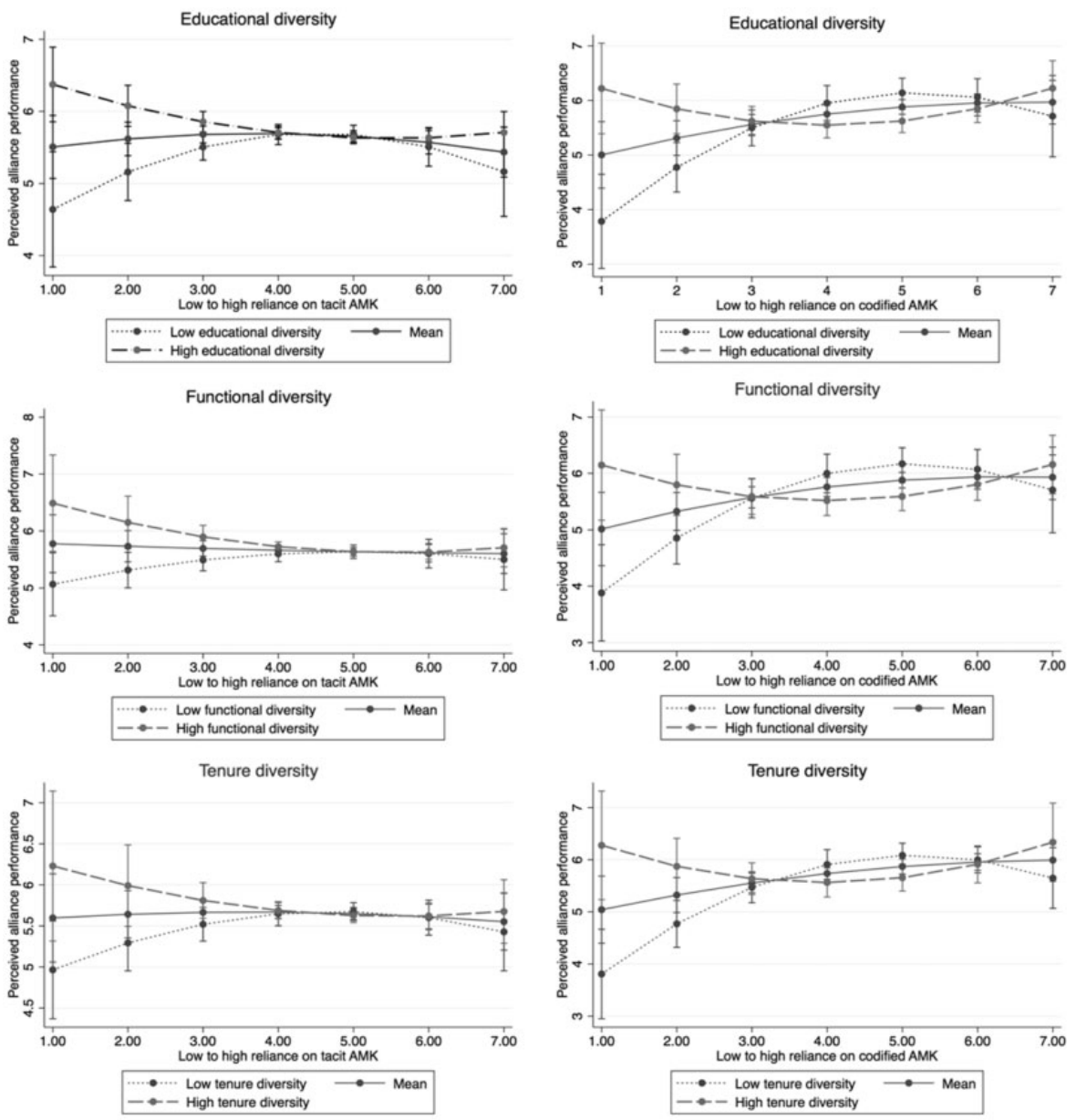

Figure 4. Predictive margins of reliance on AMK on alliance performance by DAF diversity (Models $5-10$; $95 \%$ confidence intervals).

\section{Discussion}

This study was meant to contribute to alliance research by suggesting that reliance on AMK does not benefit alliance performance indefinitely. We hypothesized that reliance on tacit and codified AMK was nonlinearly associated with alliance performance. Building on and contributing to the knowledge-based view of the firm (Nonaka, 1994; Grant, 1996), we found that the deployment of tacit AMK favors a better understanding of the alliance nuances, and thus leads to a higher quality of alliance procedures and decisions. Yet, our evidence confirms theory suggesting that tacit knowledge accumulation is likely to also trigger overconfidence and superstitious learning over a certain threshold (Zollo, 2009; Heimeriks, 2010). When reliance on experiential learning is high, the risk for firms is that stickiness becomes the norm, thus limiting knowledge transfer and sharing.

Similarly, results support a positive and significant direct effect of reliance on codified tools to guide alliance management on alliance performance. The production and update of these tools not only provide practical means to enhance decisions and actions over alliance life cycles but also focus managers' attention on the most critical aspects, giving them the opportunity to discover the rationale underlying greater alliance performance (Kale et al., 2001). However, when codification becomes the norm, organizational members might lose sight on surrounding opportunities or keep reiterate sub-optimal routines. 
We discovered that firms with the DAF experience higher alliance performance at both low and high levels of reliance on tacit and codified AMK. The DAF acts as a higher-order capability for stimulating learning and fostering accumulation of lessons learned in those firms where capabilities to leverage on tacit and codified AMK are still to be developed (Teece et al., 1997; Eisenhardt and Martin, 2000). Moreover, the DAF also counters the potential drawbacks of excessive reliance on experiential learning and codified artifacts. When the DAF is in place, obstacles to knowledge circulation can be more easily overcome. In fact, the DAF provides a legitimate place to exchange visible and rewarded alliance practices. Moreover, being forced to monitor and evaluate alliance metrics along the entire alliance life cycle, firms with the DAF are more likely to receive signals faster than those who do not have it, thus taking timely corrective actions.

Though being beneficial for the deployment of AMK, the DAF might exert a dampening effect on alliance performance, too. This impact is especially evident when the DAF is associated with low to intermediate reliance on codified AMK. When the capabilities and mechanisms to extract value from AMK have still to be fully developed, the DAF might create redundancies or discourage managers to rely on experience and trial and error experimentation. Extending prior research (Kale and Singh, 2007; Niesten and Jolink, 2015), these findings suggest that the beneficial impact of the DAF has to be set into contexts, in that it is also linked to the level of alliance management capabilities the firm has been able to develop.

Last, we investigated the moderating role of DAF attributes on the curvilinear relationship between reliance on AMK and alliance performance. We found that the beneficial impact of deploying AMK depends on the level of DAF diversity. Firms with the most diverse DAF are able to extract more value from low levels of reliance on both types AMK. Moreover, diverse DAF counters the downside effects of excessive use of experiential learning and codification.

Educational diversity seems to play the most important role in driving the positive influence of tacit AMK on alliance performance. Thanks to different educational backgrounds, managers are more likely to identify the multiple nuances of alliance know-how and share them more effectively. Conversely, tenure and functional heterogeneity, though beneficial, have less pronounced effects on the deployment of tacit AMK. Functionally diverse DAF might find it harder to develop a common understanding of tasks or, even more importantly, reconcile dissimilar, potentially conflicting points of view. The same complexity could hold for tenure diversity. Since tacit knowledge has a strong relational content, tenure diversity could reiterate organizational hierarchies, thus creating less fertile environments (Van Knippenberg et al., 2004; Van Knippenberg and Schippers, 2007).

Based on our findings, diversity has a stronger impact on the deployment of codified AMK. Educational diversity facilitates the identification of the right pieces of information, routines, and tools across the organization when reliance on codification is still low. Tenure diversity improves visibility and internal legitimacy. Working in groups with members who have different organizational tenures and functional background gives accessibility to non-overlapping knowledge (Richter et al., 2012). This leads to superior performance at low levels of reliance on codified AMK. Similarly, diverse educational backgrounds and tenure diversity facilitate the implementation of corrective actions and update outdated routines or formalized procedures when reliance on codification is high. Instead, functional diversity is likely to provide the heterogeneous perspectives necessary to change the course when things goes worse than expected, as well as discover alliance opportunities. This is especially important when reliance on codification is already high.

\subsection{Implications, limits, and future research}

This study has also important implications for practitioners. We first claim the need to invest into and properly configure multiple mechanisms to develop alliance management capabilities. Any mechanism to develop alliance management capability has a dark side. Our study gives an answer to the question about the declining effects of the alliance learning processes (Kale and Singh, 2007). Indeed, we support a curvilinear relationship between reliance on knowledge accumulation and alliance performance, suggesting that an excessive investment in some mechanisms might overweight their possible benefits. This negative impact could be countered by monitoring the marginal returns on alliances. When they turn negative, the creation of the DAF could counter this tendency and rejuvenate AMK base.

Firms in need to enhance their alliance capabilities and enjoy greater overall success certainly need to have organizational structures to manage their alliances. Yet, how to configure them in a proper way is not trivial. The DAF exerts its positive impact also based on the extent to which AMK systems are developed. Our results give empirical 
hints on how to set priorities for the development of different capability development mechanisms that keep performance high.

Finally, we tested how different attributes of DAF diversity interact with use of experience and reliance on codified tools to enhance alliance performance. The moderating role of DAF diversity points out to the benefits of educational, functional, and tenure attributes in leveraging tacit and codified AMK across the organization. The finding that firms with high DAF diversity experience higher alliance performance at low and high levels of reliance on AMK emphasizes the importance of focusing resources on those aspects that are more likely to enhance the role of the DAF in supporting the development of AMK capabilities.

Although our study provides insightful evidence on the role that different mechanisms to build alliance management capabilities have as antecedents of alliance performance, it can be extended in several ways. First, in this study we considered only higher-order alliance management skills, which are likely to be improved by firm's alliance learning processes. However, we did not address the actual firm's alliance management skills possibly required in the different stages of alliance life cycle. This choice might have hidden some important aspects of AMK, which might lie at the basis of alliance capability building. Thus, future researchers might attempt to investigate these lower-order skills and mechanisms through case studies or collecting additional data from a smaller sample of firms. Additionally, we focused on the firm's reliance on mechanisms to deploy tacit and codified AMK, rather than on the levels of AMK per se. We took this decision with the aim of investigating organization-wide alliance capabilities as antecedents of alliance performance. Future studies could be focused both on more direct measures of alliance knowledge level and to the interaction between AMK and other types of knowledge a company relies on. This would be extremely helpful to further investigate the knowledge-based antecedents of specific types of alliances, such as, for example, technology-based alliances or R\&D agreements.

Furthermore, like in most of the survey-based researches, we deployed only a perceptual measure of alliance performance provided by the same respondents, adopting a cross-sectional design. Although we demonstrated the unlikely presence of a common method bias, this choice has probably limited the robustness of the results and provided only a one-sided perspective of alliance success. Indeed, the deployment of only subjective measures might have led to the overestimation of alliance performance because managers can have potentially provided biased responses to be more socially desirable, lenient, and acquiescent. Therefore, in the future, additional analyses might be conducted through more objective alliance performance measures, such as financial or accounting indicators, considering alliance performance for each company in a specific point in time. Having a longitudinal perspective, future studies might be able to explain better the evolution of alliance capabilities over time, comparing performance and learning mechanisms in different stages of firm and alliance maturity.

Though we followed the same procedure as suggested by previous research to draw a sample as representative as possible (Dyer et al., 2001; Schilke and Goerzen, 2010), we ended up with a relatively small sample. Having access to primary data on alliances is clearly a complex task. This is the reason why samples, in survey-based alliance research, are hardly over 200 observations. Future studies could tackle this point, testing our hypotheses on larger samples or in given industries to maximize the chance to improve sample size and the generalizability of the findings.

We aimed at predicting alliance performance as a function of alliance management capabilities identified through reliance on different types of AMK. We acknowledge that it is likely that the decision to invest in the development of alliance management capability and alliance management structures (i.e., the DAF) might be endogenous and related to prior performance. However, prior research has demonstrated that a deliberate learning effect is also apparent when controlling for this (Heimeriks and Duysters, 2007). Though we were not able to directly control for financial measures of past performance, our results held controlling for firm size, that is, one of the most investigated proxies to account for slack resources (Kale et al., 2002). We also used a lead of the dependent variable to maximize the chance to rule out direct simultaneity. Future research should further test whether endogeneity drives the positive result from reliance on AMK on alliance performance, by conducting instrumental variable regressions.

Finally, we focused on the moderating role of the DAF and DAF diversity on alliance knowledge deployment. Yet, these functions play other similarly important roles, such has increasing external visibility, organizing internal coordination, or favoring alliance assessment (Dyer et al., 2001). These aspects are worth of further investigation, in relation to alliance capability building and alliance performance. This would require a finer grained investigation of the role of a DAF, rather that its mere presence as an organizational unit within the firm. Similarly, we did not account for the different organizational position that the DAF could have across companies. Having the DAF at the 
corporate level or alternatively at the business unit level could provide different benefits to the deployment of AMK. Future studies could collect more detailed data on the different organizational configuration of the DAF and how they relate both to alliance success and the successful deployment of AMK.

\section{Acknowledgment}

The authors gratefully thank Emanuele M. De Gennaro for his contribution to the data collection. The authors contributed equally to the work and are listed in alphabetical order.

\section{References}

Anand, B. N. and T. Khanna (2000), 'Do firms learn to create value? The case of alliances,' Strategic Management Journal, 21(3), $295-315$.

Ancori, B., A. Bureth and P. Cohendet (2000), 'The economics of knowledge: the debate about codification and tacit knowledge,' Industrial and Corporate Change, 9(2), 255-287.

Bantel, K. A. and S. E. Jackson (1989), 'Top management and innovations in banking: does the composition of the top team make a difference?,' Strategic Management Journal, 10(S1), 107-124.

Beckman, C. M., C. B. Schoonhoven, R. M. Rottner and S.-J. Kim (2014), 'Relational pluralism in de novo organizations: boards of directors as bridges or barriers to diverse alliance portfolios?,' Academy of Management Journal, 57(2), 460-483.

Bingham, C. B. and K. M. Eisenhardt (2011), 'Rational heuristics: the 'simple rules' that strategists learn from process experience,' Strategic Management Journal, 32(13), 1437-1464.

Buyl, T., C. Boone, W. Hendriks and P. Matthyssens (2011), 'Top management team functional diversity and firm performance: the moderating role of ceo characteristics,' Journal of Management Studies, 48(1), 151-177.

Child, J. and D. Faulkner (1998), Strategies of Cooperation: Managing Alliances, Networks, and Joint Ventures. Oxford University Press: Oxford; New York, NY.

Cohen, D. and P. Bacdayan (1994), 'Organizational routines are stored as procedural memory: evidence from a laboratory study,' Organization Science, 5(4), 554-568.

Das, T. K. and B.-S. Teng (2000), 'A resource-based theory of strategic alliances,' Journal of Management, 26(1), 31-61.

Deeds, D. L. and C. W. Hill (1996), 'Strategic alliances and the rate of new product development: an empirical study of entrepreneurial biotechnology firms,' Journal of Business Venturing, 11(1), 41-55.

Dickson, P. H. and K. M. Weaver (1997), 'Environmental determinants and individual-level moderators of alliance use,' Academy of Management Journal, 40(2), 404-425.

Draulans, J., A.-P. deMan and H. W. Volberda (2003), 'Building alliance capability: management techniques for superior alliance performance,' Long Range Planning, 36(2), 151-166.

Dyer, J. H. and H. Singh (1998), 'The relational view: cooperative strategy and sources of interorganizational competitive advantage,' Academy of Management Review, 23(4), 660-679.

Dyer, J. H., P. Kale and H. Singh (2001), 'How to make strategic alliances work,' MIT Sloan Management Review, 42(4), 37-43.

Eisenhardt, K. M. and C. B. Schoonhoven (1996), 'Resource-based view of strategic alliance formation: strategic and social effects in entrepreneurial firms,' Organization Science, 7(2), 136-150.

Eisenhardt, K. M. and J. A. Martin (2000), 'Dynamic capabilities: what are they?,' Strategic Management Journal, 21(10-11), 1105-1121.

Finkelstein, S. and D. C. Hambrick (1996), Strategic Leadership: Top Executives and Their Effects on Organizations. West Publishing Company: Saint Paul, MN.

Flood, R. L. and N. R. A. Romm (1996), 'Plurality revisited: diversity management and triple loop learning,' Systems Practice, 9(6), 587-603.

Foss, N. J. (2003), 'Bounded rationality and tacit knowledge in the organizational capabilities approach: an assessment and a reâ€evaluation,' Industrial and Corporate Change, 12(2), 185-201.

Gavetti, G. and D. Levinthal (2000), 'Looking forward and looking backward: cognitive and experiential search,' Administrative Science Quarterly, 45(1), 113-137.

Geringer, J. M. and L. Hebert (1991), 'Measuring performance of international joint ventures,' Journal of International Business Studies, 22(2), 249-263.

Golonka, M. and R. Rzadca (2013), 'Does a connection exist among national culture, alliance strategy, and leading ICT firms' performance?,' Journal of Business Economics and Management, 14(Suppl 1), S395-S412.

Grant, R. M. (1996), 'Prospering in dynamically-competitive environments: organizational capability as knowledge integration,' Organization Science, 7(4), 375-387.

Greene, W. (2010), 'Testing hypotheses about interaction terms in nonlinear models,' Economics Letters, 107(2), 291-296. 
Gulati, R. (1999), 'Network location and learning: the influence of network resources and firm capabilities on alliance formation,' Strategic Management Journal, 20(5), 397-420.

Hagedoorn, J. and J. Schakenraad (1994), 'The effect of strategic technology alliances on company performance,' Strategic Management Journal, 15(4), 291-309.

Håkanson, L (2007), 'Creating knowledge: the power and logic of articulation,' Industrial and Corporate Change, 16(1), 51-88.

Haleblian, J. and S. Finkelstein (1999), 'The influence of organizational acquisition experience on acquisition performance: a behavioral learning perspective,' Administrative Science Quarterly, 44(1), 29-56.

Hambrick, D. and P. Mason (1984), 'Upper echelons: the organization as a reflection of its top managers,' Academy of Management Review, 9(2), 193-206.

Hambrick, D. C., T. C. Cho and M.-J. Chen (1996), 'The influence of TMT heterogeneity on firm's competitive moves,' Administrative Science Quarterly, 41(4), 659-684.

Harrison, D. A. and K. J. Klein (2007), 'What's the difference? Diversity constructs as separation, variety, or disparity in organizations,' Academy of Management Review, 32(4), 1199-1228.

Heimeriks, K. H (2010), 'Confident or competent? How to avoid superstitious learning in alliance portfolios,' Long Range Planning, 43(1), 57-84.

Heimeriks, K. H., E. Klijn and J. J. Reuer (2009), 'Building capabilities for alliance portfolios,' Long Range Planning, 42(1), 96-114.

Heimeriks, K. H. and G. Duysters (2007), 'Alliance capability as a mediator between experience and alliance performance: an empirical investigation into the alliance capability development process,' Journal of Management Studies, 44(1), 25-49.

Heimeriks, K. H., G. Duysters and W. Vanhaverbeke (2007), 'Learning mechanisms and differential performance in alliance portfolios,' Strategic Organization, 5(4), 373-408.

Hoang, H. and F. T. Rothaermel (2005), 'The effect of general and partner-specific alliance experience on joint R\&D project performance,' Academy of Management Journal, 48(2), 332-345.

Hofstede, G. (1991), Cultures and Organizations. McGraw-Hill: London, UK..

Hottenrott, H. and C. Lopes-Bento (2015), 'Quantity or quality? Knowledge alliances and their effects on patenting,' Industrial and Corporate Change, 24(5), 981-1011.

Hottenrott, H. and C. Lopes-Bento (2016), 'R\&D partnerships and innovation performance: can there be too much of a good thing?,' Journal of Product Innovation Management, 33(6), 773-794.

Inkpen, A. and I. Dinur (1998), 'Knowledge management processes and international joint ventures,' Organization Science, 9(4), 454-468.

Jaccard, J. and R. Turrisi (2003), Interaction Effects in Multiple Regression, 2nd edn. Sage Publications: Thousand Oaks, CA.

Jehn, K. A., G. B. Northcraft and M. A. Neale (1999), 'Why differences make a difference: a field study of diversity, conflict and performance in workgroups,' Administrative Science Quarterly, 44(4), 741-763.

Kale, P. and H. Singh (1999), 'Alliance capability and success: a knowledge-based approach,' Academy of Management Proceedings, 1999(1), 1-6.

Kale, P. and H. Singh (2007), 'Building firm capabilities through learning: the role of the alliance learning process in alliance capability and firm-level success,' Strategic Management Journal, 28(10), 981-1000.

Kale, P. and H. Singh (2009), 'Managing strategic alliances: what do we know now, and where do we go from here?,' Academy of Management Perspectives, 23(3), 45-62.

Kale, P., J. H. Dyer and H. Singh (2001), 'Value creation and success in strategic alliances,' European Management Journal, 19(5), 463-471.

Kale, P., J. H. Dyer and H. Singh (2002), 'Alliance capability, stock market response, and long-term alliance success: the role of the alliance function,' Strategic Management Journal, 23(8), 747-767.

Kaufmann, D., A. Kraay and M. Mastruzzi (2011), The worldwide governance indicators: methodology and analytical issues. Hague Journal on the Rule of Law, 3(2), 220-246.

Kelly, D. and T. L. Amburgey (1991), 'Organizational inertia and momentum: a dynamic model of strategic change'’ Academy of Management Journal, 34(3), 591-612.

Klijn, E., J. J. Reuer, F. A. Van den Bosch and H. W. Volberda (2013), 'Performance implications of IJV Boards: a contingency perspective,' Journal of Management Studies, 50(7), 1245-1266.

Knockaert, M., D. Ucbasaran, M. Wright and B. Clarysse (2011), 'The relationship between knowledge transfer, top management team composition, and performance: the case of science-based entrepreneurial firms,' Entrepreneurship Theory and Practice, 35(4), 777-803.

Koza, M. P. and A. Y. Lewin (2000), 'Managing partnerships and strategic alliances: raising the odds of success'' European Management Journal, 18(2), 146-151.

Krishnan, R., X. Martin and N. G. Noorderhaven (2006), 'When does trust matter to alliance performance?,' Academy of Management Journal, 49(5), 894-917. 
Lavie, D., P. R. Haunschild and P. Khanna (2012), 'Organizational differences, relational mechanisms, and alliance performance,' Strategic Management Journal, 33(13), 1453-1479.

Leonard-Barton, D (1992), 'The factory as a learning laboratory,' Sloan Management Review, 34(1), 169-195.

Levinthal, D. A. and J. G. March (1993), 'The myopia of learning,' Strategic Management Journal, 14(S2), 95-112.

Levitt, B. and G. J. March (1988), 'Organizational learning,' Annual Review of Sociology, 14(1), 319-340.

Lind, J. T. and H. Mehlum (2010), 'With or without U? The appropriate test for a U-shaped relationship,' Oxford Bulletin of Economics and Statistics, 72(1), 109-118.

Maddala, G. S (1983), Limited Dependent and Qualitative Variables in Econometrics. Cambridge University Press: New York, NY.

Mihalache, O. R., J. P. Jansen, F. A. J. Van den Bosch and H. K. Volberda (2012), 'Offshoring and firm innovation: the moderating role of top management team attributes,' Strategic Management Journal, 33(13), 1480-1498.

Miller, D. (1999), 'Selection processes inside organizations: the self-reinforcing consequences of success,' in J. Baum and B. McKelvey (eds), Variations in Organization Science. Sage Publications: Thousand Oaks, CA.

Milliken, F. J. and L. L. Martins (1996), 'Searching for common threads: understanding the multiple effects of diversity in organizational groups,' Academy of Management Review, 21(2), 402-433.

Mintzberg, H. (1994), 'Rethinking strategic planning part I: pitfalls and fallacies,' Long Range Planning, 27(3), 12-21.

Nadolska, A. M. and H. G. Barkema (2014), 'Good learners: how top management team affect behavior and performance of acquisitions,' Strategic Management Journal, 35(10), 1483-1507.

Nielsen, B. B. (2007), 'Determining international strategic alliance performance: a multidimensional approach,' International Business Review, 16(3), 337-361.

Nielsen, B. B. and S. Nielsen (2009), 'Learning and innovation in international strategic alliances: an empirical test of the role of trust and tacitness,' Journal of Management Studies, 46(6), 1031-1056.

Niesten, E. and A. Jolink (2015), 'The impact of alliance management capabilities on alliance attributes and performance: a literature review,' International Journal of Management Reviews, 17(1), 69-100.

Nonaka, I. (1994), 'A dynamic theory of organizational knowledge creation,' Organization Science, 5(1), 14-37.

Nonaka, I. and G. von Krogh (2009), 'Tacit knowledge and knowledge conversion: controversy and advancement in organizational knowledge creation theory,' Organization Science, 20(3), 635-652.

Nunnally, J. C. (1970), Introduction to Psychological Measurement. McGraw-Hill: New York, NY.

Nygaard, S. and A. Russo (2008), 'Trust, Coordination and Knowledge Flows in R\&D Projects: The Case of Fuel Cell Technologies,' Business Ethics: A European Review, 17(1), 24-34.

Pisano, G. P. (1994), 'Knowledge, integration, and the locus of learning: an empirical analysis of process development,' Strategic Management Journal, 15(S1), 85-100.

Podsakoff, P. M. and D. W. Organ (1986), 'Self-reports in organizational research: problems and prospects,' Journal of Management, 12(4), 531-544.

Podsakoff, P. M., S. B. MacKenzie, J. Y. Lee and N. P. Podsakoff (2003), 'Common method biases in behavioural research: a critical review of the literature and recommended remedies,' Journal of Applied Psychology, 88(5), 879-903.

Richter, A. W., G. Hirst, D. Van Knippenberg and M. Baer (2012), 'Creative self-efficacy and individual creativity in team contexts: cross-level interactions with team informational resources,' Journal of Applied Psychology, 97(6), 1282-1290.

Rocha-Goncalves, F. and V. C. Gonçalves (2011), 'The role of the alliance management capability,' The Service Industries Journal, 31(12), 1961-1978.

Rothaermel, F. T. and D. L. Deeds (2006), 'Alliance type, alliance experience and alliance management capability in high-technology ventures,' Journal of Business Venturing, 21(4), 429-460.

Rowley, T., D. Behrens and D. Krackhardt (2000), 'Redundant governance structures: an analysis of structural and relational embeddedness in the steel and semiconductor industries,' Strategic Management Journal, 21(3), 369-386.

Russo, A. and C. Vurro (2010), 'Cross-Boundary Ambidexterity: Balancing Exploration and Exploitation in the Fuel Cell Industry,' European Management Review, 7(1), 30-45.

Sampson, R. (2005), 'Experience effects and collaborative returns in R\&D alliances,' Strategic Management Journal, 26(8), 1009-1031.

Schilke, O. and A. Goerzen (2010), 'Alliance management capability: an investigation of the construct and its measurement,' Journal of Management, 36(5), 1192-1219.

Simonin, B. L. (1997), 'The importance of collaborative know-how: an empirical test of the learning organization,' Academy of Management Journal, 40(5), 1150-1174.

Simonin, B. L. (1999), 'Ambiguity and the process of knowledge transfer in strategic alliances,' Strategic Management Journal, 20(7), 595-623.

Spender, J. C. (1996), 'Making knowledge the basis of a dynamic theory of the firm,' Strategic Management Journal, 17(S2), 45-82.

Szulanski, G. (1996), 'Exploring internal stickiness: impediments to the transfer of best practices within the firm,' Strategic Management Journal, 17(S2), 27-43. 
Teece, D. J., G. P. Pisano and A. Shuen (1997), 'Dynamic capabilities and strategic management,' Strategic Management Journal, 18(7), 509-127.

van der Vegt, G. S. and J. S. Bunderson (2005), 'Learning and performance in multidisciplinary teams: the importance of collective team identification,' Academy of Management Journal, 48(3), 532-547.

Van Knippenberg, D., C. K. De Dreu and A. C. Homan (2004), 'Work group diversity and group performance: an integrative model and research agenda,' Journal of Applied Psychology, 89(6), 1008-1022.

Van Knippenberg, D. and M. C. Schippers (2007), 'Work group diversity,' Annual Review of Psychology, 58, $515-541$.

Wang, Y. and N. Rajagopalan (2015), 'Alliance Capabilities: review and Research Agenda,' Journal of Management, 41(1), 236-260.

Zander, U. and B. Kogut (1995), 'Knowledge and the speed of the transfer and imitation of organizational capabilities-an empirical-test,' Organization Science, 6(1), 76-92.

Zollo, M. (2009), 'Superstitious learning with rare strategic decisions: theory and evidence from corporate acquisitions,' Organization Science, 20(5), 894-908.

Zollo, M. and H. Singh (2004), 'Deliberate learning in corporate acquisitions: post-acquisition strategies and integration capability in US bank mergers,' Strategic Management Journal, 25(13), 1233-1205.

Zollo, M., J. J. Reuer and H. Singh (2002), 'Interorganizational routines and performance in strategic alliances,' Organization Science, 13(6), 701-713.

Zollo, M. and S. Winter (2002), 'Deliberate learning and the evolution of dynamic capabilities,' Organization Science,13(3), $339-462$. 


\section{Appendix}

\section{Appendix A}

Review of the literature on alliance capability development

Reference Proposals/findings

Simonin (1997)

Anand and Khanna

Dyer et al. (2001)

Kale et al. (2002)

Zollo et al. (2002)

Draulans et al. (2003)

Hoang and Rothaermel (2005)

Sampson (2005)

Heimeriks and Duysters

Heimeriks et al. (2007)

Kale and Singh (2007)

Kale and Singh (2009)

Heimeriks (2010)

Schilke and Goerzen (2010)
Firms with greater collaborative experience achieve higher levels of collaborative know-how, increasing the number of tangible and intangible benefits from collaborations

Firm-level alliance capability is based on experience. However, experience is not sufficient to explain heterogeneity in alliance performance

Alliance know-how and best practices are built and leveraged within the company through the four C's, namely, capture, codify, communicate, and coach

Experience and investment in a DAF positively influence alliance performance

Experience in previous alliances enhances the performance of the focal alliance, especially if this experience has been collected in the same technological area and with the same partner

Inexperienced firms learn from trainings and individual alliance evaluations, while more experienced firms benefit from an alliance specialist and comparison of alliance evaluations

General and partner-specific alliance experience has a positive effect on alliance performance

Alliance experience has a positive relationship with alliance performance, but there are decreasing marginal returns. Prior alliance experience has a greater positive effect when the alliance activities are more uncertain or complex

Alliance capabilities partially mediate between alliance experience and alliance portfolio performance, indicating firms can improve their performance by dispersing lessons from prior alliances

Integrating mechanisms, such as trainings and know-sharing activities, have a stronger positive effect on alliance portfolio performance than institutionalizing mechanisms, especially for firms with little alliance experience. Conversely, for firms with extensive alliance experience, institutionalizing mechanisms have a stronger positive effect on alliance portfolio performance

Alliance capabilities are built thanks to a specific learning process based on articulation, codification, sharing, and internalization

Coordinative capacity and knowledge management processes (articulation, codification, sharing, and internalization) positively influence alliance performance

Learning mechanisms used to manage alliance portfolios, distinguished between integrating and institutionalizing mechanisms, nurture competence, but they might also mirror confidence

There is a positive relationship between alliance management capability and alliance portfolio performance. Alliance management capability is based on coordination, learning, sensing, and transformation and mediates the effect of alliance experience on alliance portfolio performance 


\section{Appendix B}

\section{Dependent and independent variables: factor analysis}

Alliance performance: survey items and factor analysis—component matrix

\begin{tabular}{lc}
\hline Item & Component \\
\hline 1-Your company alliances are overall successful & 0.883 \\
2-Your company is considered a "good partner" by your allies & 0.843 \\
3-The relationships between your company and the alliance partners are strong and harmonious & 0.842 \\
4-Your company has enhanced its competitive position in its existing businesses through alliances & 0.834 \\
5-Your company has not acquired new capabilities and competencies through alliances (reverse) & 0.723 \\
6 -Your company has entered new businesses or markets through alliances & 0.758
\end{tabular}

Extraction method: principal component analysis (respondents were asked to rate alliance performance by referring to alliances formed between 2012 and 2014 , $1=$ "Strongly disagree"; $7=$ "Strongly agree").

\section{$\mathrm{KMO}$ and Bartlett's sphericity tests}

Kaiser-Meyer-Olkin measure of sampling adequacy

Tacit knowledge: survey items and factor analysis—component matrix

Item

1-Company managers rely on prior experience to guide the formation or management of any alliance

2-Company managers engage in informal alliance-related knowledge-sharing and exchange activities with colleagues

3-Company managers participate in forums such as task forces or committees where they can collect their alliance

Extraction method: principal component analysis (respondents were asked to refer to alliances formed between 2012 and $2014,1=$ "Strongly disagree"; $7=$ "Strongly agree").

\section{KMO and Bartlett's sphericity tests}


Codified knowledge: survey items and factor analysis-component matrix

1-Managers follow a well-defined written process to guide the formation or management of any alliance

2-Simple resources such as checklists or guidelines are developed and used to assist alliance decision-making and/ or actions

3-Elaborated resources such as alliance manuals (containing tools, templates, or frameworks) are developed and used to assist alliance decision-making and/or action

4-The company updates the alliance checklists, guidelines, or manuals that have been developed and are in use

Extraction method: principal component analysis (respondents were asked to refer to alliances formed between 2012 and $2014,1=$ "Strongly disagree"; $7=$ "Strongly agree").

\section{KMO and Bartlett's sphericity tests}

Kaiser-Meyer-Olkin measure of sampling adequacy

Cronbach's alpha scores

\begin{tabular}{lccc}
\hline & Cronbach's alpha & Cronbach's alpha based on standardized items & Number of items \\
\hline Alliance performance & 0.890 & 0.898 & 6 \\
Tacit knowledge & 0.705 & 0.710 & 3 \\
Codified knowledge & 0.895 & 0.895 & 4 \\
\hline
\end{tabular}

